\title{
Hypercholesterolemia of obese mice with deletion of vascular adhesion protein-1 occurs without other atherosclerosis risk factor
}

\author{
Zsuzsa Iffiú-Soltész ${ }^{1,2,3}$, Sandy Bour ${ }^{2}$, François Tercé ${ }^{1,2}$, Xavier Collet $^{1,2}$, Eva Szökő ${ }^{3}$, Christian Carpéné Ç,2 $^{1,2}$ \\ ${ }^{1}$ Institut des Maladies Métaboliques et Cardiovasculaires, INSERM UMR 1048, Toulouse 31432, France. \\ ${ }^{2}$ I2MC, Université Paul Sabatier, CHU Rangueil, Toulouse 31432, France. \\ ${ }^{3}$ Department of Pharmacodynamics, Semmelweis University, Üllői 26, Budapest 1085, Hungary.
}

Correspondence to: Dr. Christian Carpéné, Institut des Maladies Métaboliques et Cardiovasculaires (I2MC), Institut National de la Santé et de la Recherche Médicale, INSERM U 1048, CHU Rangueil, Université de Toulouse, UPS, 31432 Toulouse Cedex 4,

France. E-mail: christian.carpene@inserm.fr

How to cite this article: Iffiú-Soltész Z, Bour S, Tercé F, Collet X, Szökö E, Carpéné C. Hypercholesterolemia of obese mice with deletion of vascular adhesion protein-1 occurs without other atherosclerosis risk factor. Vessel Plus 2021;5:16.

https://dx.doi.org/10.20517/2574-1209.2021.12

Received: 19 Jan 2021 First Decision: 9 Feb 2021 Revised: 10 Feb 2021 Accepted: 5 Mar 2021 Available online: 26 Mar 2021

Academic Editor: Maurizio R. Averna Copy Editor: Yue-Yue Zhang Production Editor: Yue-Yue Zhang

\begin{abstract}
Aim: Encoded by Aoc3 gene, Vascular Adhesion Protein-1 (VAP-1), also called semicarbazide-sensitive amine oxidase (SSAO), is a protein supporting leucocyte extravasation to inflammation sites and catalyzing the oxidation of primary amines. We previously observed that a genetically-modified mouse model lacking active VAP-1/SSAO is obese and hypercholesterolemic. Here, we further studied the alterations related to factors that increase or alleviate the risk of atherosclerosis.
\end{abstract}

Methods: Body weight and glucose tolerance were determined in mice homozygous for a null mutation of Aoc3 (AOC3KO) and fed standard or high-fat diet (HFD). White adipose tissue (WAT) inflammation was assessed by immunohistological observations. Cholesterol trafficking was explored by determining plasma and tissue levels and key enzyme expression. Vascular reactivity and VAP-1/SSAO activity were assessed via hydrogen peroxide release, uric acid and nitrate/nitrite levels.

Results: AOC3KO mice were devoid of VAP-1/SSAO protein and activity, while, in WT control, WAT was the richest anatomical location regarding the capacity to oxidize benzylamine. AOC3KO mice were obese but did not exhibit alteration of glucose tolerance or insulin secretion. The elevated plasma cholesterol of AOC3KO mice was further increased by HFD, with LDL cholesterol levels higher than in WT. An increased cholesteryl ester accumulation occurred in plasma, liver and WAT, with higher HMGCoA expression in WAT and slightly reduced 
SR-BI hepatic transporters. However, in AOC3KO mice, no sign of WAT inflammation was detected, while lower hydrogen peroxide release and higher nitrite levels were found in aorta and kidney.

Conclusion: The obesity of AOC3KO mice occurred with hypercholesterolemia but without other atherosclerosis risk factors, such as worsened insulin sensitivity, WAT inflammation, increased oxidative stress and reduced nitric oxide availability.

Keywords: Cholesterol, amine oxidases, adipocyte, insulin, obesity, hydrogen peroxide, liver, aorta

\section{INTRODUCTION}

Obesity is associated with chronic inflammation of white adipose tissue (WAT), which is linked to the risk of developing diabetes and characterized by an upregulation of proinflammatory chemokine expression and an increased number of macrophages. Obesity as well as hypercholesterolemia also increases the risk of atherosclerotic cardiovascular diseases ${ }^{[1]}$. Indeed, WAT not only stores lipids, but it has also been reported that its secretions (adipokines and exosomes) can directly influence the pathogenesis of atherosclerosis ${ }^{[2]}$. As we previously described a mouse model developing obesity without increased signs of inflammation in $\mathrm{WAT}^{[3]}$, it appeared of interest to further investigate whether this unusual situation may influence the risk of atherosclerosis, especially when considering that this transgenic mouse model exhibits increased circulating cholesterol levels ${ }^{[4]}$.

Indeed, the above-mentioned model is a mouse with total Aoc3 gene knock-out (AOC3KO), generated and characterized by the group of Salmi and Jalkanen ${ }^{[5]}$, and which we used to further explore WAT physiology ${ }^{[4]}$. There are four genes (Aoc1-4) encoding for mammalian copper-containing amine oxidases, which catalyze the oxidation of primary amines to aldehydes, regulate many biological processes and are linked to various diseases including inflammatory conditions and metabolic disturbances ${ }^{[6]}$. In humans and in rodents, the product encoded by Aoc3 gene is known as vascular adhesion protein-1, a membrane glycosylated enzyme exhibiting semicarbazide-sensitive amine oxidase activity (VAP-1/SSAO). This protein is found at vessel surface in endothelial cells, as well as in smooth muscle and fat cells ${ }^{[7]}$, while a soluble shed fraction also circulates in blood, at rates varying in numerous diseases ${ }^{[8]}$. Its multifaceted role remains unclear. VAP-1/SSAO is an adhesion molecule involved in leukocyte extravasation ${ }^{[7]}$, but it is also largely expressed in adipocytes and able to oxidize biogenic and xenobiotic amines. It has been proposed that it may be instrumental for the treatment of obesity and diabetes complications ${ }^{[9]}$, while many inhibitors of VAP-1/SSAO are under development as anti-inflammatory agents ${ }^{[10]}$. In addition, VAP-1/SSAO is present in atherosclerotic plaques ${ }^{[11]}$. In this context, we further explored the phenotype of AOC3KO mice, by comparing to wild-type (WT) control their dyslipidemic profile and their inflammatory and adipose cells in WAT, when fed standard or high-fat diet.

As reduced insulin sensitivity is accompanied with an inflammatory cytokine secretion by WAT, which also contributes to the development of atherosclerosis, the insulin sensitivity of the AOC3KO mice was assessed in vivo and in vitro by glucose tolerance tests and antilipolysis assays, respectively. Since inflammatory cells such as those associated with WAT inflammation in obesity alter the expression of key proteins involved in cholesterol handling ${ }^{[12]}$, we also measured in WAT the cholesteryl esters levels and the mRNA expression of carriers and enzymes involved in cholesterol metabolism. Attention was paid to 3-hydroxy-3-methylglutarylcoenzyme A reductase (HMGCoA reductase) involved in cholesterol synthesis and ATP binding cassette transporter (ABCA-1) and scavenger receptor class B type 1 (SRB1 or SR-BI, encoded by Scarb1) supporting cholesterol influx and efflux, which appeared to be downregulated in the liver of AOC3KO mouse in our recent exploration of its obese phenotype ${ }^{[4]}$. Finally, since VAP-1/SSAO activity produces 
hydrogen peroxide and ammonia when oxidizing amines, we investigated in AOC3KO mice putative changes in oxidative stress markers and nitric oxide (NO) availability in aorta, kidney and heart.

The following results confirm that Aoc3 gene disruption leads to a total SSAO/VAP-1 invalidation and a largely decreased amine oxidation capacity, at least the oxidase activity that is inhibited by semicarbazide, leaving intact that sensitive to pargyline, which is mediated by FAD-containing monoamine oxidases (MAO). This is accompanied by a reduced abundance of immune cells in the close vicinity of adipocytes. Here, we also describe that a nutritional obesogenic challenge such as high-fat diet (HFD) does not enhance these differences between WT and AOС $3 \mathrm{KO}$ mice. Moreover, the latter exhibit, alongside an altered cholesterol handling, signs of reduced oxidative stress and increased $\mathrm{NO}$ availability. Thus, in addition to the previous findings showing the importance of VAP-1/SSAO in adipocyte caveolae ${ }^{[13]}$ and adipocyte fuel selection $^{[14]}$, these results are consistent with a major function of VAP-1/SSAO in lipid handling that deserves further investigations.

\section{METHODS}

\section{Chemicals}

Benzylamine, tyramine, semicarbazide, pargyline, fatty acid-free bovine serum albumin, antiprotease cocktail and most commonly used chemicals were from Sigma-Aldrich-Merck (St Quentin Fallavier, France). $\left[{ }^{14} \mathrm{C}\right]$-benzylamine $(54 \mathrm{mCi} / \mathrm{mmol})$ came from Amersham Biosciences (Buckinghamshire, Little Chalfont, UK) and $\left[{ }^{14} \mathrm{C}\right]$-tyramine $(53 \mathrm{mCi} / \mathrm{mmol}$ ) came from NEN Life Science (Boston, MA). Liberase (Blendzyme 3) was from Roche Diagnostics (Mannheim, Germany).

\section{Animals and sample preparations}

Aoc3-/- mice were produced on a pure 129 background by the group of Jalkanen and Salmi ${ }^{[5]}$. These mice, with constitutive knock-out for the Aoc3 gene consequently to a deleted portion of exon 1, were backcrossed to a pure C57BL/6 background for more than ten generations. These homozygous Aoc3 null mutants are hereafter named $\mathrm{AOC} 3 \mathrm{KO}$, to distinguish from another strain, harboring a mutation in the Aoc3 gene sequence that renders the protein catalytically inactive, and called AOC3 knock-in mice (AOC3KI, not studied here $)^{[4,15]}$. Male and female mice of the WT and AOC3KO genotypes were housed at constant temperature $\left(20-22{ }^{\circ} \mathrm{C}\right)$ and with a 12 -h light-dark cycle. All mice had free access to food and water. In our breeding conditions, the $\mathrm{AOC} 3 \mathrm{KO}$ line had some trouble in reproduction, as the litters of homozygous offspring appeared to be of lower size than in WT. This parameter could not be exactly quantified since AOC3KO mothers eat their runts after birth. Nevertheless, the remaining pups followed normal growth and, after weaning, were included in this phenotyping study for seven months. As a consequence, the number of adult mice housed per cage varied from one to four, depending on genotype and gender. All mice used for this study were handled in accordance with the European Communities Council Directives relating to the conduct of animal experimentation. Mice were weighed weekly, and subgroups were randomly constituted for the determination of individual daily urine production or for glucose tolerance tests as already described ${ }^{[16]}$. At the end of this non-invasive follow-up, mice were euthanized and aorta, WAT, kidney, heart and liver were frozen for subsequent measurements or mRNA extraction as previously described ${ }^{[3,4]}$. Adipocytes were immediately isolated from intra-abdominal white adipose tissues (INWAT: perirenal plus perigonadal plus retroperitoneal fat pads) by liberase digestion for subsequent measurement of lipolytic activities or frozen for mRNA quantification or amine oxidase activity. The other fraction collected alongside adipocytes after WAT digestion, namely the stromavascular fraction (SVF), was frozen prior mRNA quantification. Plasma was collected for the determination of endocrine and metabolic parameters. 


\section{High-fat diet challenge and non-invasive explorations}

Male mice of both genotypes were fed a high-fat diet that provided $45 \%$ of calories from fat given ad libitum for 20 weeks (HFD, at $4.73 \mathrm{kcal} / \mathrm{g}$, from UAR, France) and compared to mice fed with a standard pelleted $\operatorname{diet}(\mathrm{SD}, 3.85 \mathrm{kcal} / \mathrm{g})$.

\section{VAP-1/SSAO immunodetection}

Homogenates of subcutaneous WAT were prepared at pH 7.5 in RIPA buffer: $0.01 \mathrm{M}$ Tris, $0.15 \mathrm{M} \mathrm{NaCl}, 2$ mM Sodium vanadate, 2 mM PMSF, 1\% Sodium deoxycholate, $0.1 \%$ SDS and 1\% NP40. After 15 min centrifugation at $5000 \mathrm{~g}$, the lipid-free infranatant was stored on ice during protein determination. Then, SDS-PAGE was performed in $12 \%$ acrylamide mini-gels with $20 \mu \mathrm{g}$ of proteins solubilized in Laemli buffer during $120 \mathrm{~min}$ at $200 \mathrm{~V}$. Protein content was determined using Bradford reagent (Bio-Rad). After transfer and blocking steps, nitrocellulose membranes were incubated overnight at $4{ }^{\circ} \mathrm{C}$ with a TK $10-79$ antibody solution (kindly given by Pr. S. Jalkanen, Turku, Finland) at 1/2000 dilution. After washing and exposure to peroxidase-coupled secondary antibody, the membrane was treated for chemiluminescent detection according to the provider recommendations (ECL Western Blotting Detection Analysis, Amersham).

\section{Immunohistochemistry of immune cells in adipose depots}

Subcutaneous WAT was fixed in 95\% ethanol and embedded in paraffin. Endogenous peroxidase activity was inhibited by hydrogen peroxide (3\% in PBS) before labeling. Immunolabeling for CD45 was performed using monoclonal rat anti-mouse CD45 as first antibody (1/50 dilution from BD-Pharmingen, Erembodegem, Belgium). The secondary antibody was biotin-conjugated donkey anti-rat antibody (diluted 1/200 from Jackson Immunoresearch, Baltimore, USA). Streptavidin-HRP was the third layer (diluted 1/1000 from Jackson Immunoresearch). Leukocytes were then visualized with 3-amino-9-ethylcarbazole (AEC, Dako Glostrup, Denmark). The sections were counterstained with hematoxylin before microscopical observation.

\section{Amine oxidase activity}

Oxidase activity was measured using ${ }^{14} \mathrm{C}$-benzylamine or ${ }^{14} \mathrm{C}$-tyramine according to the radiochemical method previously described ${ }^{[17]}$.

\section{RNA extraction, reverse transcription and real time PCR}

Liver, subcutaneous WAT (400 mg), adipocytes and SVF were homogenized in $2 \mathrm{~mL}$ of RLT buffer plus 20 $\mu \mathrm{L} \beta$-mercaptoethanol. After lipid elimination by chloroform extraction, total RNA was extracted using RNeasy mini Kit (Qiagen, Courtaboeuf, France) according to the supplier's instructions. Then, $0.5 \mu \mathrm{g}$ total RNA was reverse transcribed using random hexamers and Superscript II Reverse Transcriptase (Invitrogen, Cergy Pontoise, France). A reaction was performed in parallel without Reverse Transcriptase (RT-) to estimate genomic DNA contamination. Real-time PCR was performed starting with $6.25 \mathrm{ng} \mathrm{cDNA}$ and both sense and antisense oligonucleotides listed in Table 1 in a final volume of $20 \mu \mathrm{L}$ using the SYBR Green TaqMan Universal PCR Mastermix (Eurogentec, Angers, France). Oligonucleotide primers were designed using Primer Express software (Perkin-Elmer Life Sciences, Courtaboeuf, France). Fluorescence was monitored in GeneAmp 7500 detection system instrument (Applied Biosystems). Analysis of the $18 \mathrm{~S}$ ribosomal RNA was performed in parallel using the Ribosomal RNA Control Taqman Assay Kit (Applied Biosystems) in order to normalize gene expression. Results are expressed as units relative to $18 \mathrm{~S}$ expression

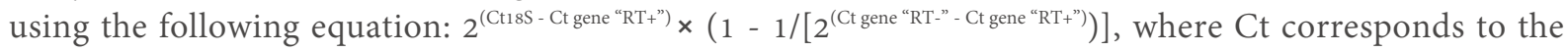
number of cycles needed to generate a fluorescence threshold.

\section{Lipolytic activity of adipocytes}

Glycerol release was used as an index for adipocyte lipolysis, considering that FFA release exhibits parallel 
Table 1. Primer sequences for genes of interest

\begin{tabular}{|c|c|}
\hline \multirow[t]{2}{*}{ Mouse gene } & Sense/antisense \\
\hline & oligonucleotides \\
\hline Aoc2 & $\begin{array}{l}\text { CCTTCTCAGGTAGTTCAGCTCCAT } \\
\text { TGGTCACTAACTACTACGTGTCATCATT }\end{array}$ \\
\hline Aoc3 & $\begin{array}{l}\text { GTGGTCAGATCCGTGTCTACCTT } \\
\text { CCTGTGGCGTGGAATTTGA }\end{array}$ \\
\hline Glut4 & $\begin{array}{l}\text { CCGGATTCCATCCCACAAG } \\
\text { CATGCCACCCACAGAGAAGA }\end{array}$ \\
\hline$F 4 / 80$ & $\begin{array}{l}\text { TGACAACCAGACGGCTTGTG } \\
\text { GCAGGCGAGGAAAAGATAGTGT }\end{array}$ \\
\hline CD11b & $\begin{array}{l}\text { TCGGACGAGTTCCGGATTC } \\
\text { TGTGATCTTGGGCTAGGGTTTC }\end{array}$ \\
\hline CD45 & $\begin{array}{l}\text { ACATGCTGCCAATGGTTCTG } \\
\text { GTCCCACATGACTCCTTTCCTATG }\end{array}$ \\
\hline Scarb1 & $\begin{array}{l}\text { CGCCGACCCTGTGTTGTC } \\
\text { GGATGTCTAGGAACAAGGAATGCT }\end{array}$ \\
\hline SREBP2 & $\begin{array}{l}\text { CTCCTTTCTGCCTCTGGTTCTC } \\
\text { GCAAAATGCTCTCTGGTGCAA }\end{array}$ \\
\hline$A B C A-1$ & $\begin{array}{l}\text { ATCGTGTCTCGCCTGTTCTCA } \\
\text { GTCCTTAATGCTGGTATCTCTTTGG }\end{array}$ \\
\hline HMGCoAred & $\begin{array}{l}\text { GACAAGAAGCCTGCTGCCATA } \\
\text { CGGCTTCACAAACCACAGTCT }\end{array}$ \\
\hline
\end{tabular}

changes in our experimental conditions ${ }^{[18]}$.

\section{Neutral lipid analysis in plasma and tissues}

Lipids were extracted from plasma, liver or SCWAT according to Bligh and Dyer ${ }^{[19]}$ and molecular species of neutral lipids (cholesterol, cholesteryl esters, diacylglycerols and triacylglycerols) were quantified by gas liquid chromatography as already described ${ }^{[20]}$.

\section{Western blotting of apoproteins and scavenger receptors}

Separation of proteins from total plasma (for apolipoprotein AI) or LDL/VLDL fractions isolated from plasma samples by precipitation with phosphotungstate $/ \mathrm{MgCl}_{2}$ (for apo $\mathrm{B} 48$ and $\mathrm{B} 100$ ) was performed using 4\%-16\% SDS-PAGE. Immunoblot analysis was performed using sheep polyclonal antibodies against mouse apo AI and apo B100/B48 (1:5000, kindly provided by C. Mazure, INRAE Clermont-Ferrand) and horseradish peroxidase coupled-anti sheep polyclonal secondary antibody (Sigma-Aldrich). For SR-BI Western blotting, tissues were homogenized at $4{ }^{\circ} \mathrm{C}$ in $1.5 \mathrm{~mL}$ of PBS containing $0.1 \mathrm{mM}$ phenylmethylsulfonyl fluoride, $1 \mu \mathrm{M}$ pepstatin, $1 \mathrm{mM}$ iodoacetamide and $1 \mathrm{mM}$ phenanthroline by using a Turrax blender and then Dounce homogenizer. Lysates were centrifuged $\left(250 \mathrm{~g}, 4^{\circ} \mathrm{C}, 5 \mathrm{~min}\right)$ to eliminate tissue debris, then resuspended in PBS with antiprotease cocktail. After 10\% SDS-PAGE and nitrocellulose membrane transfer, immunoblot of SR-BI was performed by chemiluminescence detection (PerkinElmer Life Sciences) using rabbit antipeptide polyclonal antibodies against mouse SR-BI protein (Abcam) and horseradish peroxidase coupled-anti rabbit polyclonal secondary antibody.

\section{Plasma levels and tissue biomarkers}

Blood glucose was measured using the glucose oxidase method (Biomériux, France). Ultrasensitive Insulin Elisa kit was obtained from Mercodia (Uppsala, Sweden) and used for plasma. Other plasma levels were determined with a Cobas-Mira ${ }^{+}$multi-analyzer, according to the manufacturer' instructions (Roche, Neuilly, France). The different types of lipoproteins in plasma were separated by low-pressure liquid chromatography, and, then, in the different fractions, cholesterol (VLDL, LDL and HDL) and triacylglycerol 
(TG) measurements were performed using ABX Pentra Cholesterol CP kit (ABX Pentra Diagnostics, Montpellier, France) and “Triglycerides Enzymatiques PAP 150” kit (BioMérieux, Marcy L’Etoile, France). For free fatty acid assays, the kit was Wako NEFA-HR2 kit (Wako Chemicals GmbH, Neuss, Germany). AGE plasma levels were measured by their native fluorescence $(370 / 440 \mathrm{~nm})^{[21]}$. To this aim, samples were diluted 30 times with $\mathrm{pH} 7.4$ phosphate buffered saline (PBS), mixed with chloroform to remove lipoproteins and centrifuged $\left(15,000 \mathrm{~g}, 4^{\circ} \mathrm{C}, 5 \mathrm{~min}\right)$ just before fluorescence readings. Analyses of circulating fructosamine (using a colometric assay based on nitrotetrazolium blue reduction) and uric acid (using a uricase-peroxidase method) were adapted to 96-well microplates.

Tissue nitrate and nitrite concentrations were measured by a capillary electrophoresis method ${ }^{[22]}$. Briefly, samples were sonicated in five volumes of $0.1 \mathrm{M} \mathrm{NaOH}$ to destroy proteins. $\mathrm{pH}$ was adjusted to approximately 7 by an equal volume of $0.09 \mathrm{M}$ acetic acid. Samples were placed in boiling water for $3 \mathrm{~min}$, then cooled on ice and proteins were removed by centrifugation $\left(2000 \mathrm{~g}, 4{ }^{\circ} \mathrm{C}, 10 \mathrm{~min}\right)$. Supernatant was used for injection (100 mbar for $0.75 \mathrm{~min}$ ). Electrophoretic separation was performed by Prince capillary electrophoresis system (PrinceTechnology, Emmen, The Netherlands). Separations were carried out in uncoated fused silica capillaries ( $100 \mu \mathrm{m}$ i.d., $365 \mu \mathrm{m}$ o.d., $70 \mathrm{~cm}$ total length, $55 \mathrm{~cm}$ to the detector, Polymicro Technology, Phoenix, AZ, USA) using $30 \mathrm{mM}$ sulfate- $\beta$-alanine $\mathrm{pH} 3.8$ buffer, constant current: $110 \mu \mathrm{A}$. The apparatus was equipped with a UV detector, set at $214 \mathrm{~nm}$. The calibration curve was fitted for $0-100 \mu \mathrm{M} \mathrm{KNO}_{3}$ and $\mathrm{NaNO}_{2} ; 100 \mu \mathrm{M} \mathrm{KBrO}_{3}$ was used as the internal standard. Hydrogen peroxide production was determined on tissue homogenates using an AmplexRed-based spectrofluorometric method as previously specified ${ }^{[23]}$. Urine was collected for $24 \mathrm{~h}$ in individual metabolic cages, and then uric acid and uremic toxins (urea and creatinine) were determined with kits from Horiba ABX Medical (Montpellier, France) as previously described ${ }^{[24]}$.

\section{Statistical analyses}

The results are presented as means \pm standard error of the mean (SEM) of (n) observations. Statistical significance was assessed by use of Student's $t$ test for each phenotypic parameter. Analyses were performed with Prism 6 for Mac OS X (from GraphPad software, Inc). NS denotes a non-significant difference $(P>$ 0.05).

\section{RESULTS}

\section{Biochemical validations of the targeted disruption of VAP-1/SSAO in AOC3KO mice}

Figure 1 shows that no VAP-1/SSAO protein was present in AOC3KO mice. Western blotting did not detect immunoreactive VAP-1/SSAO in adipocyte preparation from AOC3KO mouse, while it was present in WT. This was in perfect agreement with the already reported lack of expression of the Aoc 3 gene in various tissues of AOC3KO mice, evidenced by real-time $\mathrm{PCR}^{[4]}$.

These findings are in line with the already reported lack of amine oxidase activity in AOC3KO mice ${ }^{[3,4]}$. In these previous studies, the amine oxidase activity was expressed per milligram of protein, as is usual for enzymatic activity. However, one of the criticisms raised about the comparison of the amine oxidase richness between various organs when using this expression ${ }^{[4]}$ is that the protein content is highly variable from one tissue to another. As we found that WAT was richer in VAP-1/SSAO activity than many other organs, and since WAT has the lower protein content (approximately $2 \mu \mathrm{g} / \mathrm{mg}$ wet weight, as a consequence of the large lipid droplets it contains), one could hypothesize that such low protein content was creating a bias when expressing enzyme velocity per milligram of protein. In the present study, we therefore determined the DNA content in the different tissues studied and expressed VAP-1/SSAO activity as nanomoles of radiolabeled benzaldehyde formed per minute per milligram of DNA. Thus, the ${ }^{14} \mathrm{C}-$ 


\section{MW WT AOCзKO}

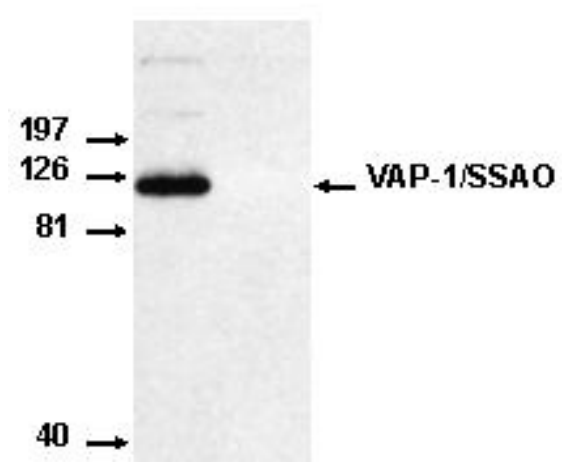

Figure 1. Lack of VAP-1/SSAO protein in the adipose tissue of AOC3KO mice. The Western blot compared under identical conditions an adipose tissue preparation from WT mouse (left) to that of AOC3KO mouse (right) with a chemiluminescent detection of immunoreactive proteins revealed by mouse anti-VAP-1 antibody (TK $10-79$ at $2.5 \mu \mathrm{g} / \mathrm{mL}$ ).

benzylamine oxidation sensitive to semicarbazide inhibition was determined in intra-abdominal WAT (INWAT), subcutaneous WAT (SCWAT), aorta, liver and kidney [Figure 2].

Moreover, we also determined MAO-dependent oxidation of ${ }^{14} \mathrm{C}$-tyramine (resistant to semicarbazide but abolished by pargyline) to verify whether other amine oxidases were altered in AOC3KO mice, and MAO activity was also expressed as nanomoles of oxidation product/min/mg DNA. In WT mice, INWAT and SCWAT were the tissues with higher SSAO activity, having a rate twice higher than aorta, while liver and kidney were less able to oxidize benzylamine. As expected, SSAO activity was abolished in all tested tissues of $\mathrm{AOC} 3 \mathrm{KO}$ mice [Figure 2]. Regarding MAO activity, there was no significant difference between $\mathrm{AOC} 3 \mathrm{KO}$ and WT mice, with liver being richer than the other organs [Figure 2]. Taken together, these verifications confirmed the targeted deletion of VAP-1/SSAO in AOC3KO mice and reinforced the paradigm of a high expression of Aoc3 gene in WAT and aorta when compared to other organs.

\section{Signs of lowered inflammation in the adipose tissue of AOC3KO mice}

An immunohistological study of SCWAT sections was performed using a monoclonal antibody anti-mouse $\mathrm{CD} 45$ to detect immune cells. In sections of paraffin-embedded adipose tissue, the size of CD45 positive inflammatory cells was obviously lower than that of the lipid-laden adipocytes. However, the immune cells were found in the close vicinity of adipocytes in WT mouse WAT [Figure 3A]. Examples of the limited density of $\mathrm{CD}_{4} 5^{+}$cells in the close environment of adipocytes of AOC3KO mice are shown in Figure $3 \mathrm{~B}$.

Indeed, most of the $\mathrm{CD} 45^{+}$cells were located within the vessels irrigating the fat depot, suggesting that the extravasation of leukocytes was limited under Aoc3 targeted deletion. This observation was in line with the previously reported lower expression of the pan-leukocyte marker CD45 mRNA in WAT of AOC3KO mice when compared to $\mathrm{WT}^{[3]}$. Additionally, the apparent cell size of the adipocytes was larger in AOC3KO than in WT mice, a qualitative observation that was not quantified [Figure 3] but agreed with the previously reported excessive fattening of $\mathrm{AOC} 3 \mathrm{KO}$ mice $\mathrm{e}^{[3,4]}$. All these observations were also dealing with the overweight phenotype found for both male and female mice with null mutation of Aoc3 [Figure 4].

Since obesity is often associated with altered glucose tolerance and insulin resistance, an in vivo intraperitoneal (i.p.) glucose tolerance test was performed in these mice when $22-25$ weeks old. 

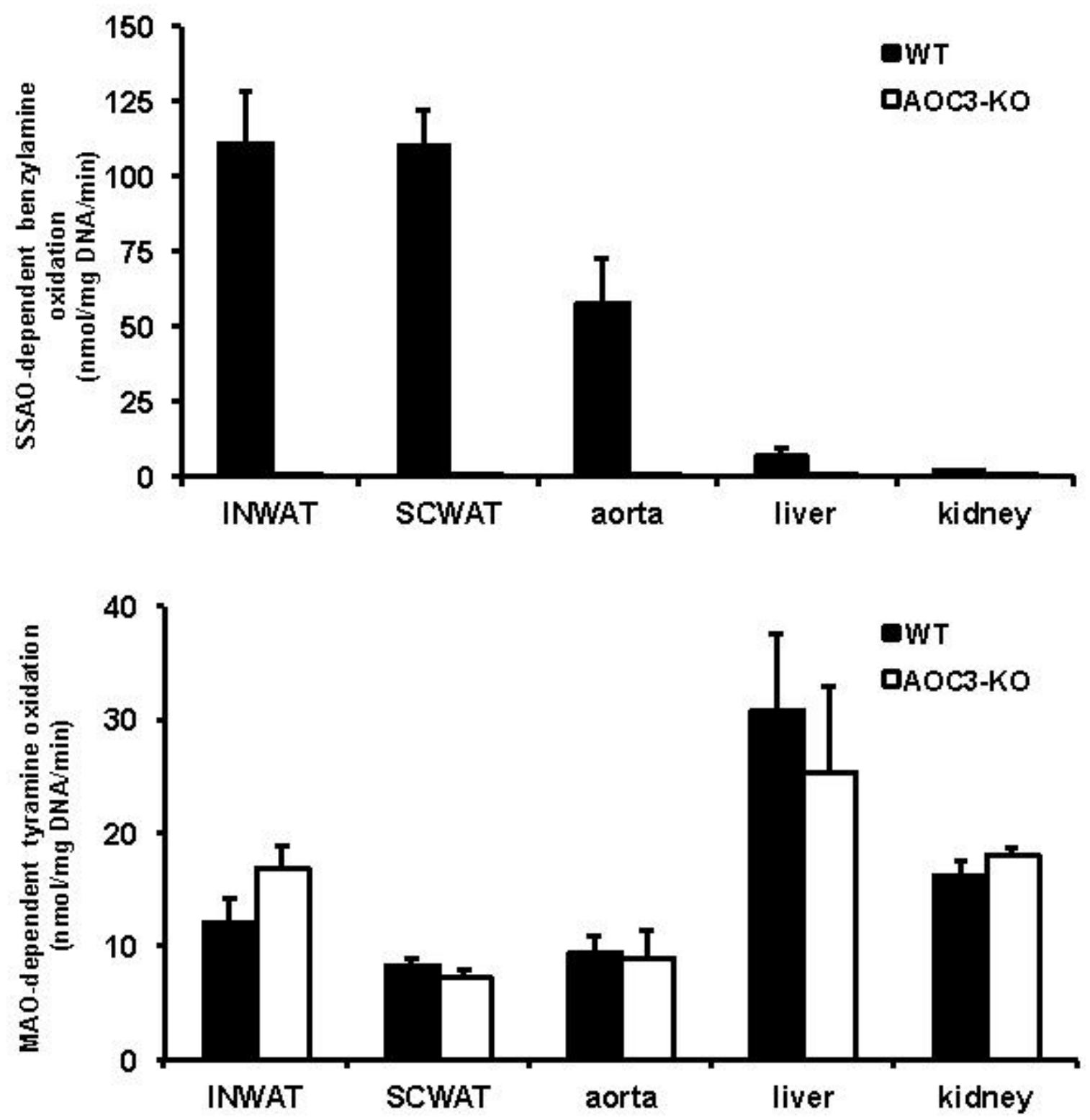

Figure 2. Targeted deletion of Aoc3 gene in mouse abolishes VAP-1/SSAO oxidative activity without notable compensation of MAO activities. SSAO-dependent oxidation of $\left[{ }^{14} \mathrm{C}\right]$-benzylamine (top) or MAO-dependent oxidation of $\left[{ }^{14} \mathrm{C}\right]$-tyramine (bottom) is represented for various organs from WT (closed columns) and AOC3KO (open columns) mice. Each column is mean $\pm \mathrm{SEM}$ of eight WT and AOC3KO mice. For the SSAO activity (top), the difference between the two genotypes is at $P<0.001$, irrespective of the tissue, while there is no genotype effect on MAO activity (bottom). Enzymatic oxidase activity of tissue homogenates is normalized per mg of DNA since protein content was highly different among the tested organs. INWAT: Intra-abdominal white adipose tissues; SCWAT: subcutaneous white adipose tissues.

\section{AOC3KO mice do not exhibit altered glucose tolerance}

It is worth noting that glucose tolerance was not altered in AOC3KO mice since their hyperglycemic excursion was very similar to that found in the WT control when saline bolus was injected 15 min before an i.p. glucose load of $1 \mathrm{~g} / \mathrm{kg}$ [Figure 5]. At this step, we took advantage of the availability of a compound that influences blood glucose control in a SSAO-dependent manner, to verify whether its anti-hyperglycemic action could be detected in VAP-1/SSAO-null mice. Indeed, hexakis (benzylamonium) decavanadate 
A WT
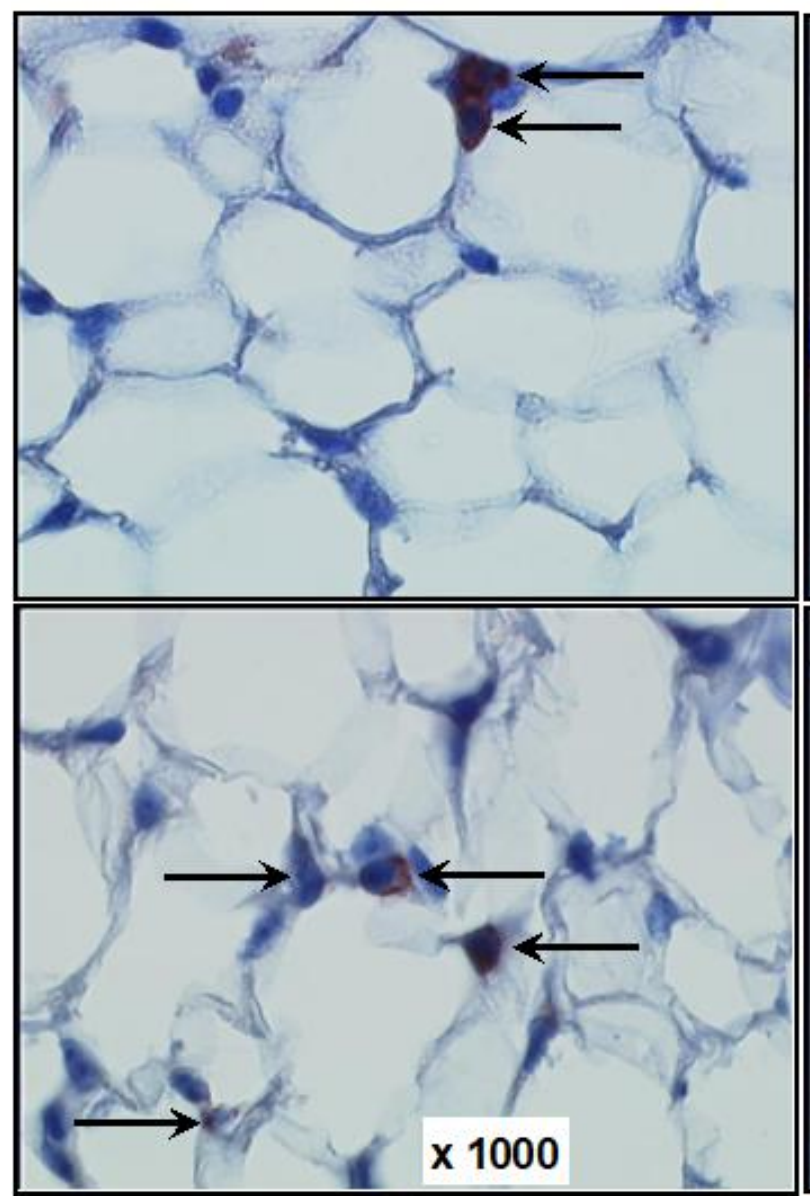

Figure 3. Immunohistological localization of leukocytes $\left(C D 45^{+}\right)$on paraffin sections of inguinal white adipose tissue from: WT mice (A): and AOC3KO mice (B). Photographs are representative of images with similar results in three animals per genotype. Nuclei are stained in blue; arrows identify CD45 cells (reddish), which appear at the vicinity of adipocytes (large white droplets) in WT, while they are more limited to the lumen of vessels (yellow cross) in AOC3KO.

(B6V10) is a benzylamine-vanadate complex salt designed by GenMedica Therapeutics (Barcelona, Spain) that exerts various in vitro insulinomimetic effects and that exhibits antihyperglycemic actions, which are dependent on its oxidation by SSAO ${ }^{[25,26]}$. When $7 \mu \mathrm{mol}$ of $\mathrm{B} 6 \mathrm{~V} 10$ were injected to WT and AOC3KO mice $15 \mathrm{~min}$ before the glucose tolerance test, the compound improved glucose tolerance in WT but not in AOC3KO mice [Figure 5].

Therefore, the total lack of VAP-1/SSAO was not impairing the glucose tolerance in mouse, but the presence of $A o c 3$ gene product was crucial for the effect of the B6V10 compound on in vivo glucose handling. This observation confirmed that the mechanism of action of B6V10 was mainly dependent on amine oxidase activity.

During these tests, insulin levels were measured at $15 \mathrm{~min}$ after glucose load and were similar in all studied groups (WT saline: $0.74 \pm 0.10$; WT B6V10: 0.59 \pm 0.08; AOC3KO saline: $0.72 \pm 0.05$; AOC3KO B6V10: 0.71 $\pm 0.07 \mu \mathrm{g} / \mathrm{L}, n=9-11)$. Thus, there was no evident influence of Aoc3 gene invalidation on glucose-stimulated insulin secretion and it could be advanced that the antihyperglycemic effect of B6V10 found in WT was not 


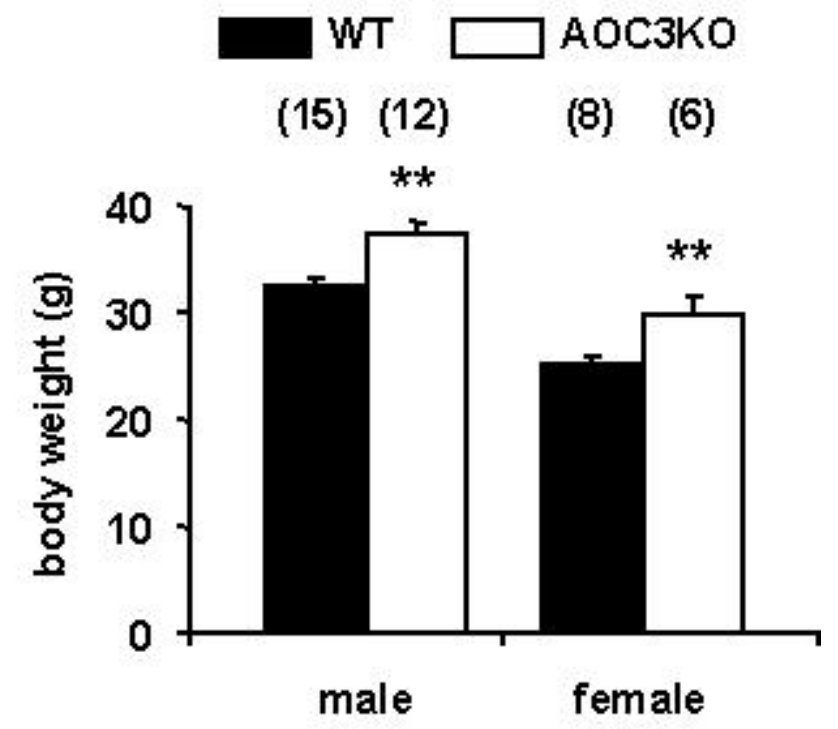

Figure 4. Body weight of male and female mice is influenced by targeted deletion of Aoc3 gene. Each column is mean $\pm \mathrm{SEM}$ of the number of seven-month-old animals indicated in parentheses. Different from corresponding age-matched control (WT, dark column) at: ${ }^{\star \star} P<0.01$.

the consequence of an increased insulin release.

Alongside the facilitation of glucose entry in peripheral tissues, the antilipolytic effect of insulin is also one of the effects that are impaired in insulin resistance. Thus, we investigated the antilipolytic responses of isolated fat cells to evaluate a putative influence of Aoc3 gene null mutation on insulin responsiveness. In fat cells from AOC3KO mice, $100 \mathrm{nM}$ insulin inhibited $32.8 \% \pm 5.3 \%$ of the lipolytic effect of $10 \mathrm{nM}$ isoprenaline, while this percentage of inhibition was $46.4 \% \pm 8.9 \%$ in WT adipocytes $(n=9$, NS). In addition, no change in the expression of GLUT4 mRNA was found (not shown), arguing for adequate equipment in insulin-regulated glucose transporters in AOC3KO. This lack of significant differences between the genotypes indicated that, despite being obese, the AOCзKO mice did not exhibit overt signs of insulin resistance.

\section{AOC3KO mice exhibit altered plasma cholesterol levels}

As the clear overweight phenotype of $\mathrm{AOC} 3 \mathrm{KO}$ mice occurred without noticeable complication regarding glucose handling or WAT inflammation, this model could be tentatively qualified as "healthy obese". However, deleterious changes in cholesterol plasma levels were recently reported in such mice ${ }^{[4]}$. Whether they were indicative of perturbations directly related to Aoc3 gene deficiency or triggered by other unknown mechanisms remains unclear since hypercholesterolemia was not an outcome reported so far by most of the studies on this mouse model, mainly used for immunity research ${ }^{[5,15,27-29]}$, and to a lesser extend for investigations on metabolic and cardiovascular diseases ${ }^{[3,30-33]}$.

We confirmed in the present study that, in AOC3KO mice, the cholesterol content was larger in the three types of plasma lipoproteins separated, namely the very-low-, low- and high-density lipoproteins (VLDL, $\mathrm{LDL}$, and $\mathrm{HDL}$ ) [Figure 6]. In the group of $12 \mathrm{AOC} 3 \mathrm{KO}$ mice used for the above-mentioned supplementary studies, the triacylglycerols carried by the VLDL fraction were also higher in AOC3KO than in WT mice, as shown in Figure 6. Differently from humans, in mouse plasma, the larger amount of cholesterol was found in the HDL fraction ${ }^{[34]}$, while the triacylglycerols were mainly carried in larger lipoproteins, especially 

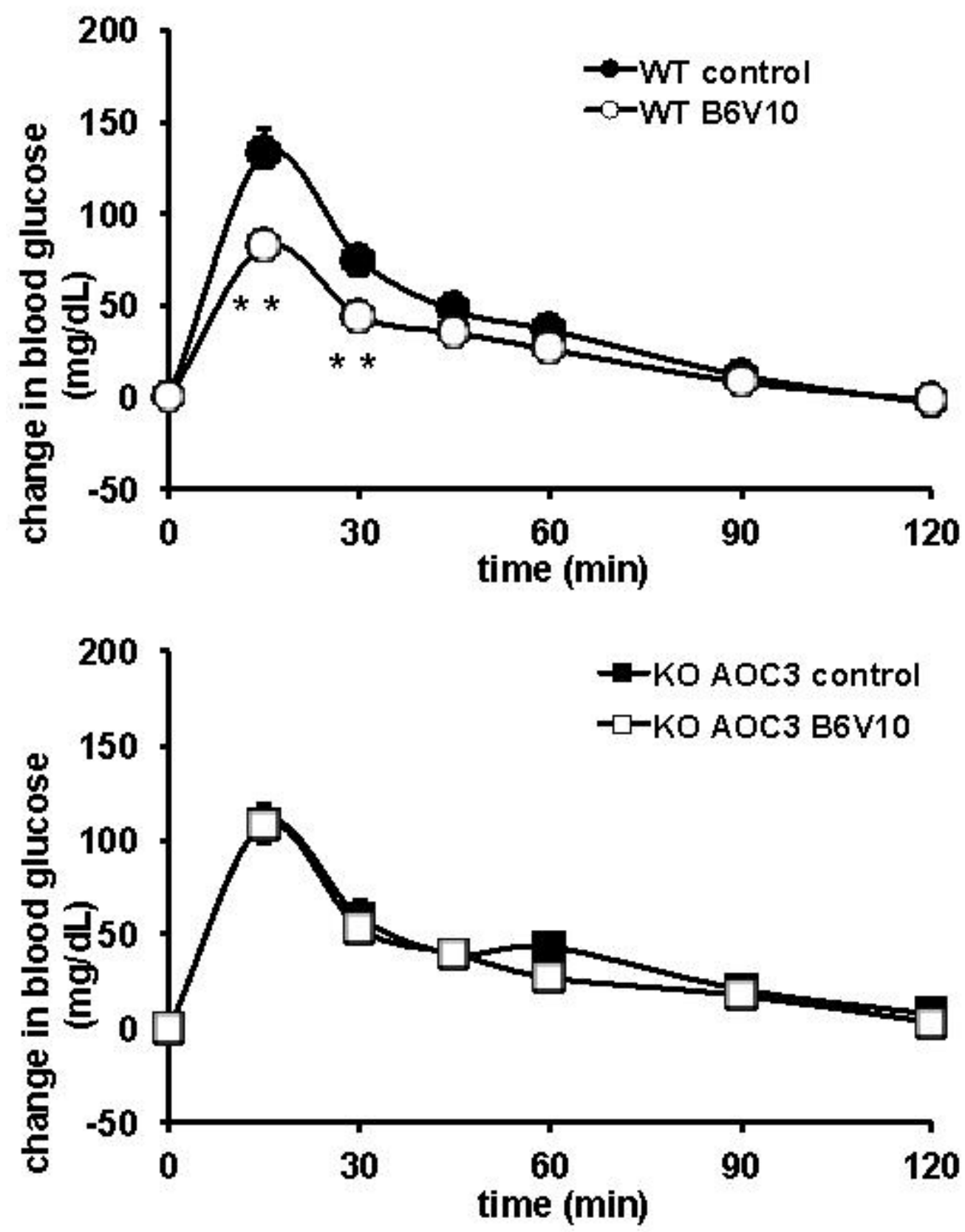

Figure 5. Glucose tolerance test after single injection of hexakis (benzylammonium) decavanadate (B6V10, open symbols) or saline (control, closed symbols) in WT (top) and AOC3KO (bottom) male mice. B6V10 (7 $\mu \mathrm{mol} / \mathrm{kg}$ ) or $\mathrm{NaCl} 0.9 \%$ were i.p. administered 15 min before glucose load ( $1 \mathrm{~g} / \mathrm{kg}$, i.p.) at time 0 . Each point is mean $\pm \mathrm{SEM}$ of the change in blood glucose, normalized to t0 levels for 12 mice per group. In several occurrences, the SEM bar lies within the symbol: circle for WT and square for AOC3KO. Different from corresponding control at: **.

\section{VLDL.}

To further explore whether the defective lipid handling and increased atherogenic susceptibility could be amplified in such obesity-prone and hypercholesterolemic mice under challenging conditions, it was decided to subject AOC3KO mice to HFD. 


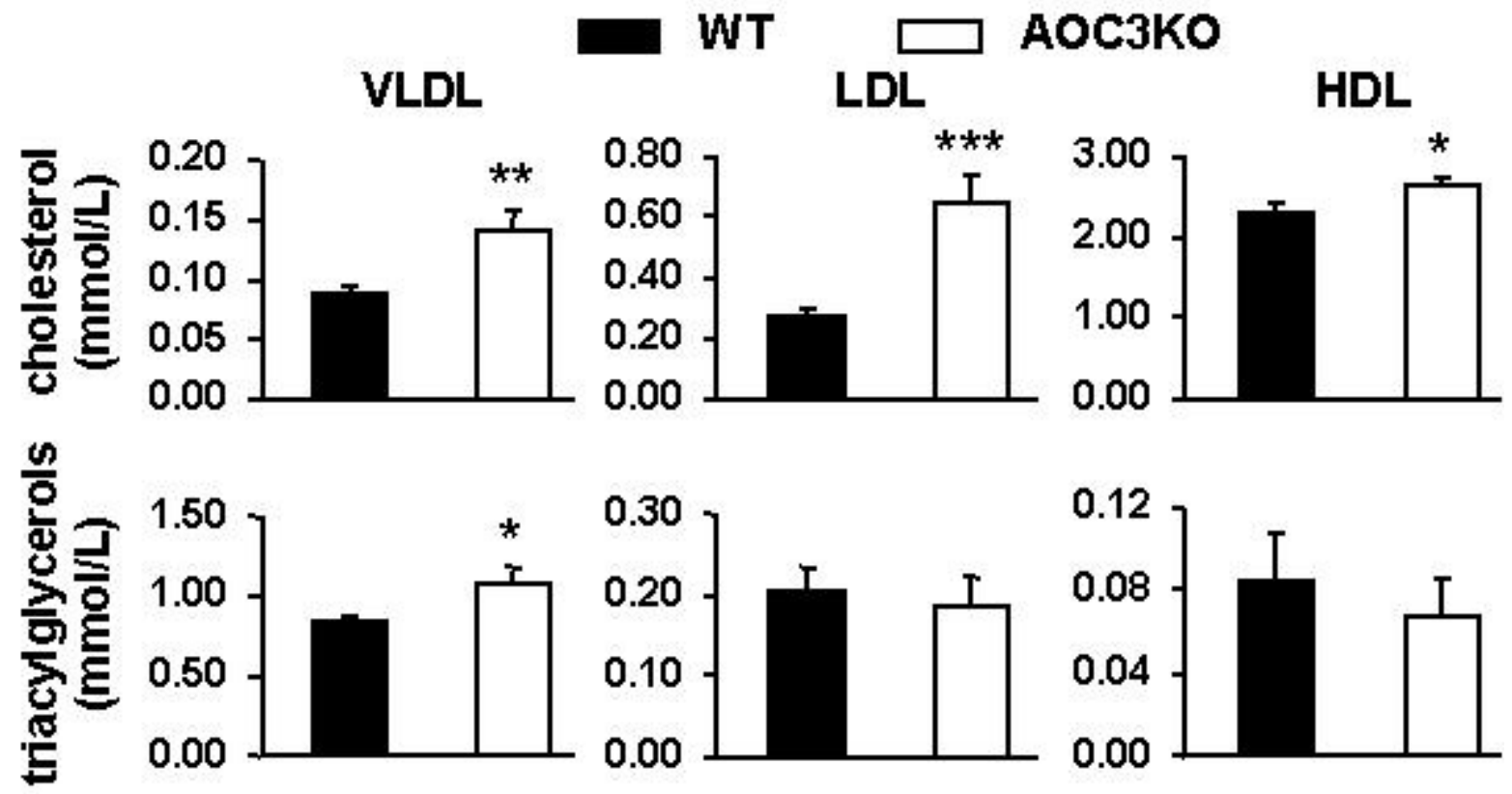

Figure 6. Circulating levels of cholesterol in lipoprotein fractions separated by low pressure liquid chromatography. Each column is mean \pm SEM of 11 WT (black) and 12 AOC3KO(white) mice. Different from WT at: ${ }^{\star} P<0.05$; ${ }^{\star \star} P<0.01 ;{ }^{\star \star \star} P<0.001 . P<0.01$.

\section{AOC3KO mice do not exhibit increased susceptibility to high-fat feeding}

Four groups of male mice were constituted and weighed weekly for 20 weeks, namely the WT and AOC $3 \mathrm{KO}$ groups fed ad libitum with standard diet (SD), together with the WT HFD and AOC3KO HFD groups, subjected to high-fat diet (HFD). With the standard diet, overweight phenotype was observed for the AOC3KO genotype [Figure 7A]. Although increasing body weight gain, the HFD did not exacerbate a higher phenotypic difference: AOC3KO HFD mice were not heavier than WT HFD [Figure 7B]. On the day of sacrifice, the body mass was $42.8 \pm 1.0$ vs. $44.7 \pm 1.1 \mathrm{~g}$ for WT HFD and AOC3KO HFD groups $(n=8$ and 12, respectively, NS). More precisely, the larger fat deposition found in AOC3KO when compared to WT, observed in some previous experiments ${ }^{[3,4]}$ but not all ${ }^{[5,33]}$, was confirmed for three anatomical locations of fat depots in SD-fed mice [Figure 7C]. Surprisingly, this difference between WT and AOC3KO disappeared when mice were subjected to HFD [Figure 7D]. The nutritional obesogenic challenge was efficient since both WT HFD and AOC3KO HFD groups were heavier and fatter than their corresponding SD control. However, the AOC3KO mice were less prone than the WT ones to further enhance their overweightness and enlarge their already hypertrophied fat stores.

The stromavascular fraction (SVF) of WAT, which contains all the cell types except mature adipocytes, has been shown to play a role in the adaptations to lipid storage, especially when WAT cannot correctly manage excessive lipid accumulation and increases its inflammation state, leading to unhealthy obesity ${ }^{[35]}$. Thus, several gene expressions were explored in this fraction (containing preadipocytes, immune, endothelial and stem cells). F4/80, a widely used marker of murine macrophage populations, was clearly increased by HFD, including in $\mathrm{AOC} 3 \mathrm{KO}$ mice. It was also the case for $\mathrm{CD} 11 \mathrm{~b}$ (known as Integrin alpha $\mathrm{M}$ ), a marker of cells from the innate immune system [Table 2]. This suggested that the relative proportion of macrophages and natural killer cells was increasing in the SVF of WAT under HFD stress condition, in WT and in AOC3KO mice, while the overall amount of the $\mathrm{CD} 45^{+}$immune cells was stable in the SVF [Table 2]. Such changes were therefore indicative of an adaptation to HFD of the respective proportions of specialized inflammatory cells present in the SVF rather than a strong leukocyte infiltration in WAT. 
Table 2. mRNA abundance of macrophages and inflammatory cells markers in the stromavascular fraction of adipose tissue from WT and АОСЗКО mice fed a standard diet or a high-fat diet for 20 weeks

\begin{tabular}{lllll}
\hline mRNA abundance & WT SD & AOC3KO SD & WT HFD & AOC3KO HFD \\
\hline F4/80 (relative unit) & $17.7 \pm 2.1$ & $21.5 \pm 3.2$ & $40.3 \pm 4.3^{\dagger \dagger}$ & $42.6 \pm 3.9^{\dagger \dagger}$ \\
CD11b (relative unit) & $7.7 \pm 1.1$ & $10.0 \pm 1.9$ & $20.6 \pm 1.9^{\dagger \dagger}$ & $22.4 \pm 5.7^{\dagger \dagger}$ \\
CD45 (relative unit) & $4.7 \pm 0.4$ & $4.2 \pm 0.8$ & $4.8 \pm 1.5$ & $4.4 \pm 0.5$ \\
\hline
\end{tabular}

mRNAs were determined as described in Methods. Mean \pm SEM of 6-8 mice. No significant difference was found between WT and AOC3KO. In each genotype, difference between SD and HFD significant at: ${ }^{\dagger \dagger} P<0.01$. SD: Standard diet; HFD: high-fat diet.
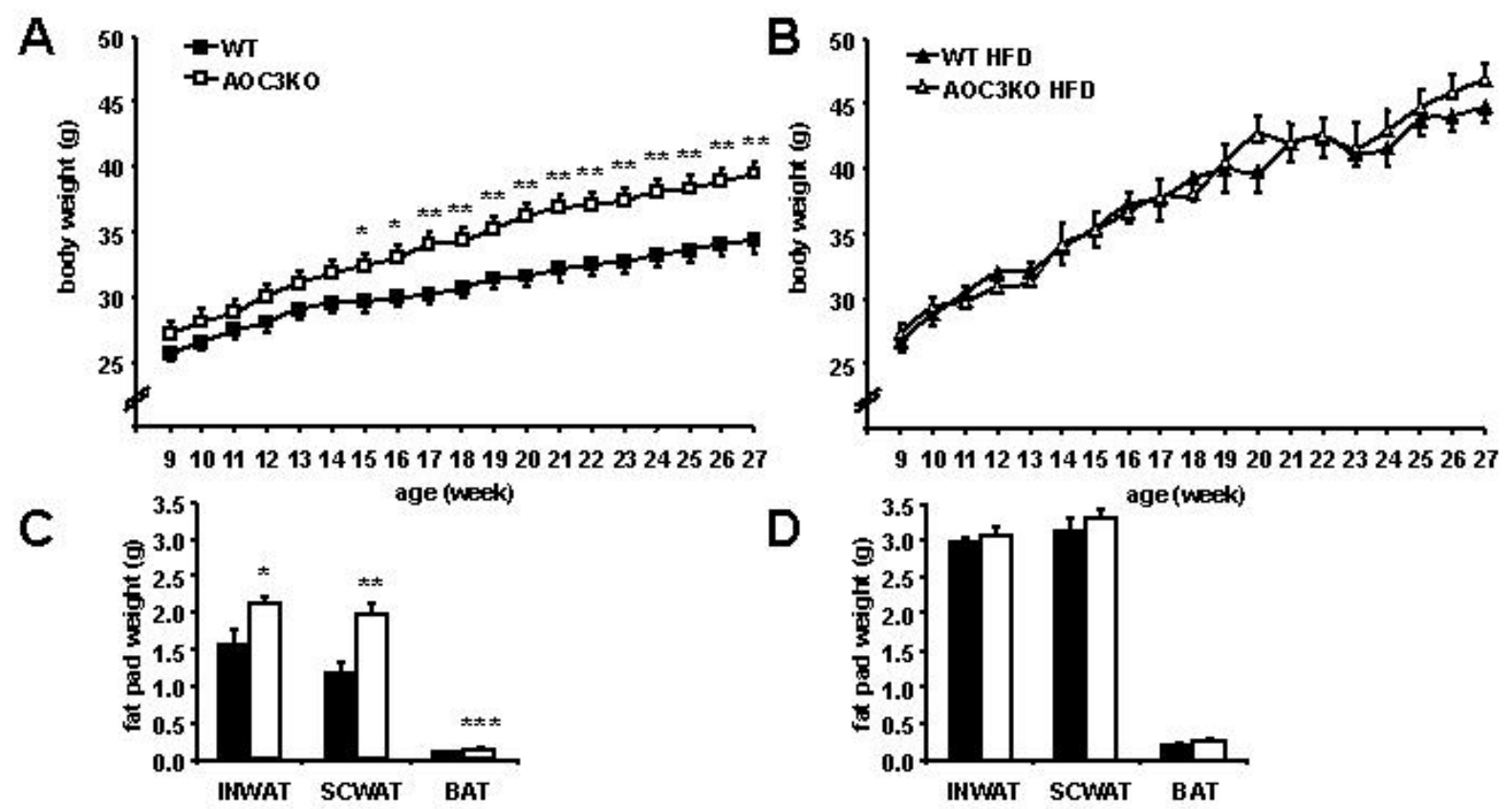

Figure 7. Body weight gain and adiposity of WT and AOC3KO male mice fed a standard diet (SD) or a high-fat diet (HFD). (A) WT (black squares) and AOC3KO (open squares) male mice were weighed weekly when fed ad libitum with a standard diet. (B) Body weight evolution for WT (black triangles) and AOC3KO (open triangles) male mice challenged with high-fat feeding for 20 weeks. Mean \pm SEM from 11 mice per group in (A,C) and from 8 WT HFD and 12 AOC3KO HFD mice in (B, D). Significant influence of genotype on body weight at: ${ }^{\star} P<0.05 ;{ }^{\star \star} P<0.01$. (C, D) At the age of 28 weeks, intra-abdominal (INWAT), subcutaneous (SCWAT) and brown adipose tissues (BAT) were dissected and weighed. Differences between WT (black columns) and AOC3KO mice (white columns) significant at: ${ }^{\star} P<0.05 ;{ }^{* *} P<0.01 ;{ }^{* \star *} P<0.001$.

We also took advantage of the separation of fat cells from the SVF to verify that the Aoc3 gene expression in adipocytes was not altered by HFD: the Aoc 3 mRNA abundance was $79.1 \pm 22.8$ and $66.5 \pm 8.5$ relative units in WT and WT HFD, respectively, while it did not exceed $0.9 \pm 0.3$ and $1.1 \pm 0.1$ in adipocytes from AOC3KO and AOC3KO HFD mice, respectively. In parallel, the Aoc2 mRNA was present in adipocytes at the lower limit of detection irrespective of genotype or diet (not shown). Accordingly, there was no detectable benzylamine oxidation by adipocytes from AOC3KO HFD (not shown). All these verifications corroborated that VAP-1/SSAO activity in mouse WAT is mainly dependent on Aoc3 gene expression, which is elevated in adipocytes.

The determination of plasma levels for several endocrino-metabolic parameters indicated that HFD worsened insulin sensitivity and lipid metabolism, but it confirmed that this challenge failed in increasing the phenotypic differences between WT and AOC3KO mice [Table 3]. Both genotypes became 
Table 3. Circulating levels in WT and AOC3KO mice fed a standard diet (SD) or a high-fat diet

\begin{tabular}{lllll}
\hline Circulating levels & WT SD & AOC3KO SD & WT HFD & AOC3KO HFD \\
\hline Blood glucose $(\mathrm{mmol} / \mathrm{L})$ & $5.58 \pm 0.39$ & $6.06 \pm 0.29$ & $6.46 \pm 0.31$ & $6.24 \pm 0.39$ \\
Insulin $(\mu \mathrm{g} / \mathrm{L})$ & $1.20 \pm 0.17$ & $1.37 \pm 0.25$ & $4.71 \pm 1.07^{\dagger \dagger}$ & $3.31 \pm 0.48^{\dagger \dagger}$ \\
Triacylglycerols $(\mathrm{mmol} / \mathrm{L})$ & $1.12 \pm 0.07$ & $1.34 \pm 0.07^{\star}$ & $1.34 \pm 0.10$ & $1.37 \pm 0.11$ \\
Free fatty acids $(\mu \mathrm{g} / \mathrm{L})$ & $0.81 \pm 0.04$ & $0.70 \pm 0.04$ & $0.80 \pm 0.05$ & $0.75 \pm 0.06$ \\
MDA $(\mu \mathrm{mol} / \mathrm{L})$ & $24.1 \pm 1.3$ & $28.1 \pm 1.1^{\star}$ & $35.1 \pm 3.1^{\dagger \dagger}$ & $37.6 \pm 2.8^{\dagger \dagger}$ \\
\hline
\end{tabular}

Blood glucose, plasma insulin and plasma metabolite levels were determined after 20 weeks of diet and overnight fasting. Mean \pm SEM of 8-11 mice. Difference between WT and AOC3KO significant at: ${ }^{\star} P<0.05$. Difference between SD and HFD significant at: ${ }^{\dagger \dagger} P<0.01$. MDA: Malondialdehyde equivalents.

hyperinsulinemic under HFD, while they maintained normoglycemic levels. The modest hypertriglyceridemia, seen in the AOC3KO SD-fed group, was not amplified under HFD conditions, as both genotypes exhibited similar TG levels. While no change in free fatty acid plasma levels was noted, the lipid peroxidation marker MDA, which was slightly higher in AOC3KO than in WT under SD, was increased after HFD but did not exhibit further difference between genotypes [Table 3].

In agreement with our previous results [Figure 6 and those $\mathrm{in}^{[4]}$ ], with normal feeding, the total cholesterol was more elevated in $\mathrm{AOC} 3 \mathrm{KO}$ than in $\mathrm{WT}$ [Figure $8 \mathrm{~A}$ ], while circulating levels were significantly elevated by HFD, overpassing the level of $4 \mathrm{mmol} / \mathrm{L}$ in both genotypes [Figure $8 \mathrm{~B}$ ]. However, AOC3KO mice did not exhibit larger alterations than WT, at least when considering total cholesterol (influence of genotype factor was borderline at $P<0.06$ in HFD instead of being $<0.001$ in SD). Only the LDL cholesterol remained higher in AOC3KO HFD than in WT HFD [Figure 8]. In addition, a highly significant positive linear relationship was observed between circulating cholesterol and body weight among the four groups studied [Figure $8 \mathrm{C}$ ]. A similar positive link with body weight was found for INWAT and SCWAT mass, but not for blood glucose, which remained highly controlled among the four experimental groups (not shown).

Since HFD did not reveal stronger alterations in mice with null mutation of Aoc3 gene than in WT, it was decided to not further explore other putative changes after this nutritional intervention. Instead, attempts to analyze deeper key elements involved in cholesterol trafficking were made in additional sets of AOC3KO mice and WT control fed a normal diet.

\section{Cholesterol trafficking in AOC3KO mice}

First, we verified whether increased circulating cholesterol was a reproducible outcome in the different groups of $\mathrm{AOC} 3 \mathrm{KO}$ mice we sequentially explored in our previous investigations for immune and endocrino-metabolic issues ${ }^{[3,4,31]}$ and in the present work. A compilation of all our accumulated data led to definitely consider that, on a large number of observations, the AOC3KO mice are hypercholesterolemic, at least at six months of age under our breeding conditions. Irrespective of the gender, plasma cholesterol levels were $2.41 \pm 0.12 \mathrm{mmol} / \mathrm{L}$ of plasma for a total of $40 \mathrm{WT}$ mice and $2.98 \pm 0.11 \mathrm{mmol} / \mathrm{L}$ for a total of 37 AOC3KO mice $(P<0.001)$. When considering gender differences, males exhibited higher cholesterol plasma levels than females, as it is generally admitted for laboratory mice ${ }^{[34]}$, but, again, the AOC $3 \mathrm{KO}$ mice were hypercholesterolemic when compared to WT.

Plasma cholesterol was, in mmol/L: $2.74 \pm 0.12$ and $1.79 \pm 0.17$ in male WT and female WT, respectively $(n$ $=26$ and $14, P<0.001)$, while it was $3.30 \pm 0.13$ and $2.59 \pm 0.14$ in male AOC3KO and female AOC $3 \mathrm{KO}(n=$ 20 and $17, P<0.001)$, respectively. The invalidation of Aoc3 gene resulted there in a larger hypercholesterolemic influence in females $(P<0.001)$ than in males $(P<0.003)$. 
total cholesterol

HDL-cholesterol

LDL-cholesterol

A SD

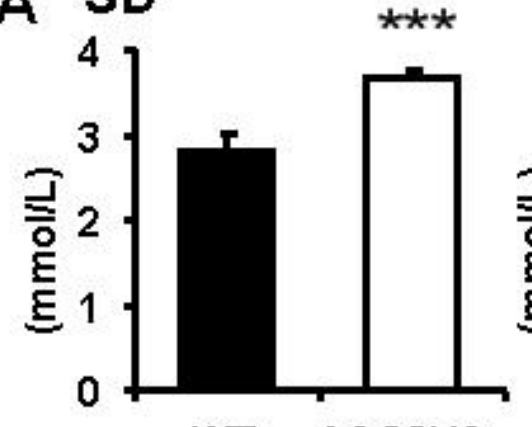

WT AOC3KO

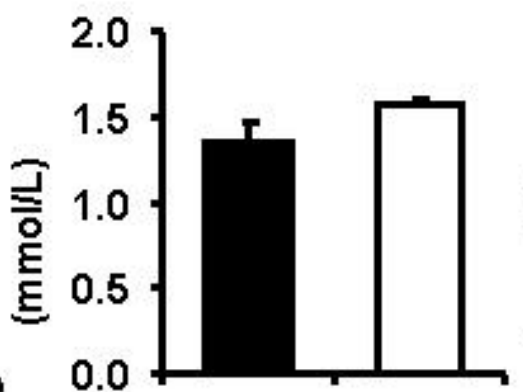

WT AOC3KO

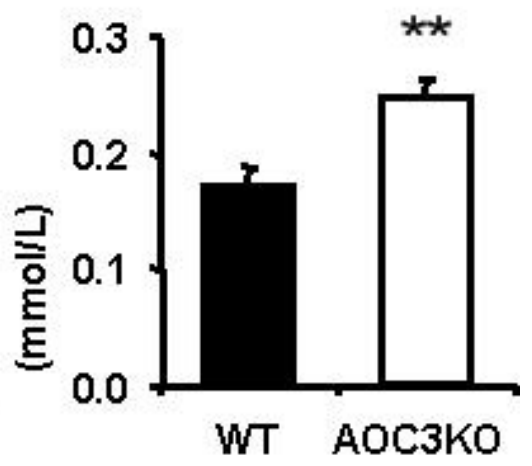

B HFD
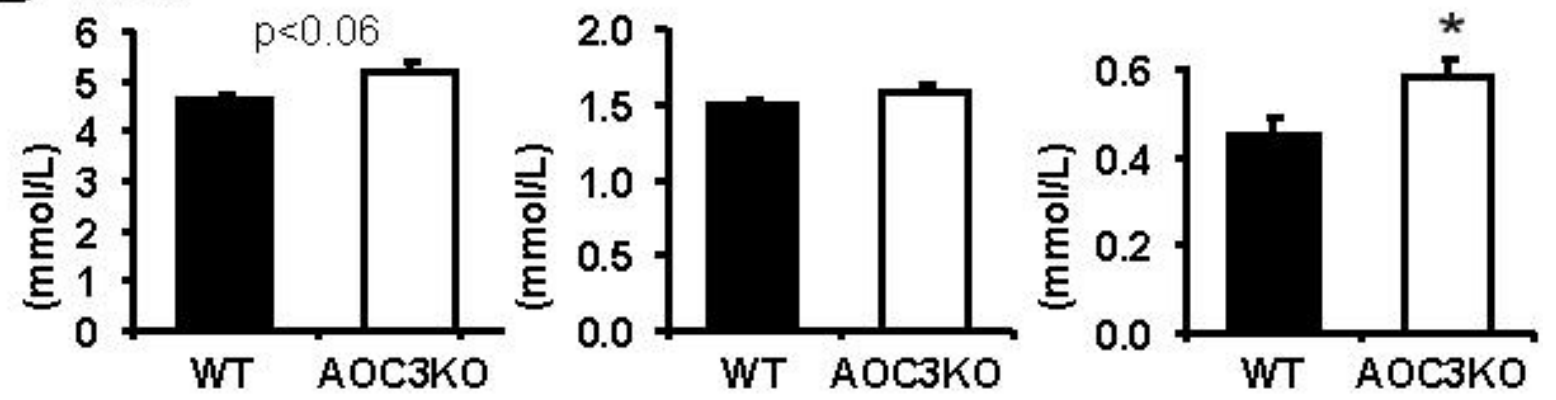

c

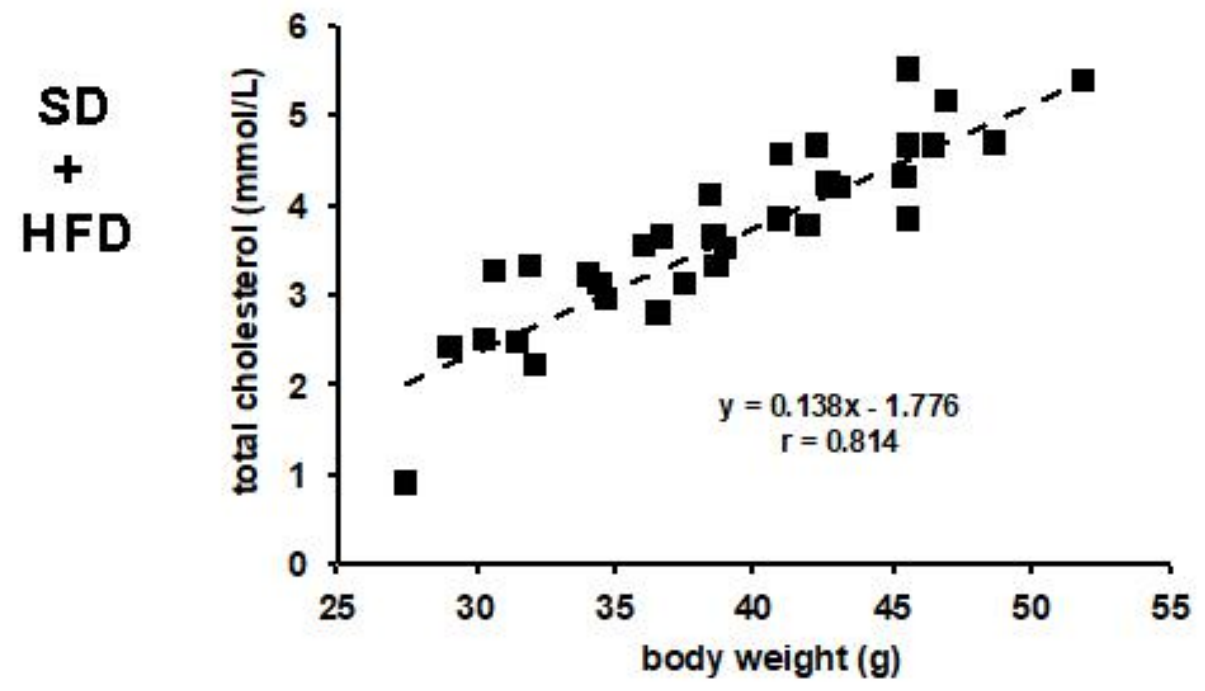

Figure 8. HFD increases cholesterol levels in WT and AOC3KO mice. Mean \pm SEM of eight WT (black columns) and AOC3KO (open columns) mice fed SD and eight mice each for HFD group. Note the change of y-scale in standard diet (SD) groups (A) for total (left) and LDL-cholesterol (right) only, when compared to HFD group (B). The VLDL fraction was not determined on its own but included in total cholesterol. Differences between WT and KO mice significant at: ${ }^{\star} P<0.05,{ }^{\star \star} P<0.01,{ }^{\star \star \star} P<0.001$. (C) All mice used for the determinations in $(A, B)$ are plotted for cholesterol levels vs. body weight, with the equation of the linear relationship (dotted line) indicated.

In an attempt to decipher the mechanisms underlying such hypercholesterolemia, we determined the amounts of several apoproteins in plasma and key elements of cholesterol trafficking in liver and WAT. 
There was no significant difference in the intensity of immunoreactive apo B100, apo B48 or apo A1 between WT and AOC3KO (not shown). Therefore, the lack of change in these main proteins of VLDL/LDL, chylomicrons and HDL, respectively, seemed to indicate that it was the composition of the lipoproteins that was altered in the blood of $\mathrm{AOC} 3 \mathrm{KO}$ mice rather than their quantity. Since we recently reported that there is a lower expression of the gene scavenger receptor class B type 1 (Scarb1) in the liver of AOC3KO mice $e^{[4]}$, we investigated whether its product, namely the scavenger receptor class B type 1 (SRB1, also known as SR-BI), which functions as a receptor for HDL, was less abundant in the liver of AOC3KO mice. When determining the relative abundance of SR-B1 in the liver, a slight decrease of $10 \%$ was evidenced by densitometry analysis of the SR-B1 positive band (the heavier of the immunoreactive proteins, $\mathrm{X}$. Collet and F. Tercé, unpublished data): relative units were $60.4 \pm 4.6$ and $55.0 \pm 4.3$ for WT and AOC3KO, respectively (eight mice per genotype, $P<0.05$ ). Figure 9 shows an integral Western blot with four mice/genotype. Although limited, this apparent downregulation of SR-B1 protein was in agreement with the $45 \%$ reduction of Scarb1 expression we reported previously ${ }^{[4]}$. Taken together, these findings suggest that the hepatic uptake of cholesteryl esters from high-density lipoproteins was limited in AOC3KO mice and participated at least in part in the increased blood cholesterol. This prompted us to determine cholesteryl ester levels in plasma, liver and WAT.

In plasma, all classes of circulating lipids were higher in AOC3KO than in WT, including the cholesteryl esters [Figure 10]. Nevertheless, the ratio of free cholesterol-to-esterified cholesterol remained unchanged between the two strains.

The hepatic content of cholesteryl esters was clearly more elevated in AOC3KO than in WT, and this influenced the amount of total cholesterol, which was also higher [Figure 10]. However, there was not more hepatic triacylglycerols (TG) in AOC3KO than in WT, and, when normalized to body weight, the liver mass was not significantly different between the two genotypes. While it cannot be advanced that hepatosteatosis was clearly established in AOC3KO mice, the excess of cholesteryl esters, which can occur spontaneously in liver of rodents such as hamsters ${ }^{[36]}$, is also recognized to favor alterations of hepatocyte functions. This was probably the reason that, in contrast to the immunohistological observations and PCR analyses performed in WAT (above-reported results and those $\mathrm{in}^{[3]}$ ), there was no sign of reduced inflammation in liver, since CD45 mRNA levels were not significantly lower in AOC3KO liver than in WT ( $n=8$; NS, not shown).

Regarding WAT, the increase of cholesteryl esters found in AOC3KO was also significant, but the bulk quantity of TG that characterizes WAT, irrespective of the genotype studied, likely interfered with the determination of the other lipids, as denoted by the mandatory change of scale in Figure 10. Hence, cholesterol esterification seemed excessive in AOC3KO mice.

As we previously performed a comparison of key regulators of cholesterol trafficking in liver of AOC3KO mice ${ }^{[4]}$, we extended this comparative approach to INWAT adipocytes and did not find the abovementioned difference for Scarb1 expression. The expressions of the LDL receptor, the sterol regulatory element-binding protein $2(S R B E P-2)$ and the ATP binding cassette transporter $(A B C A-1)$ were also unchanged (not shown). The only difference found between WT and AOC3KO adipocytes was a 30\% increased expression of $H M G C o A$ reductase $\mathrm{mRNA}$ in the latter $(0.53 \pm 0.04 \mathrm{vs} .0 .70 \pm 0.05$ relative units, $n=$ $8, P<0.05$, not shown), which could be responsible for an enhanced cholesterol synthesis in WAT. Although there was not higher cholesterol in WAT from AOC3KO, contrarily to liver and plasma [Figure 10], this elevated HMGCoA reductase could be considered as one of the mechanisms supporting the hypercholesterolemia of $\mathrm{AOC} 3 \mathrm{KO}$ mouse. 


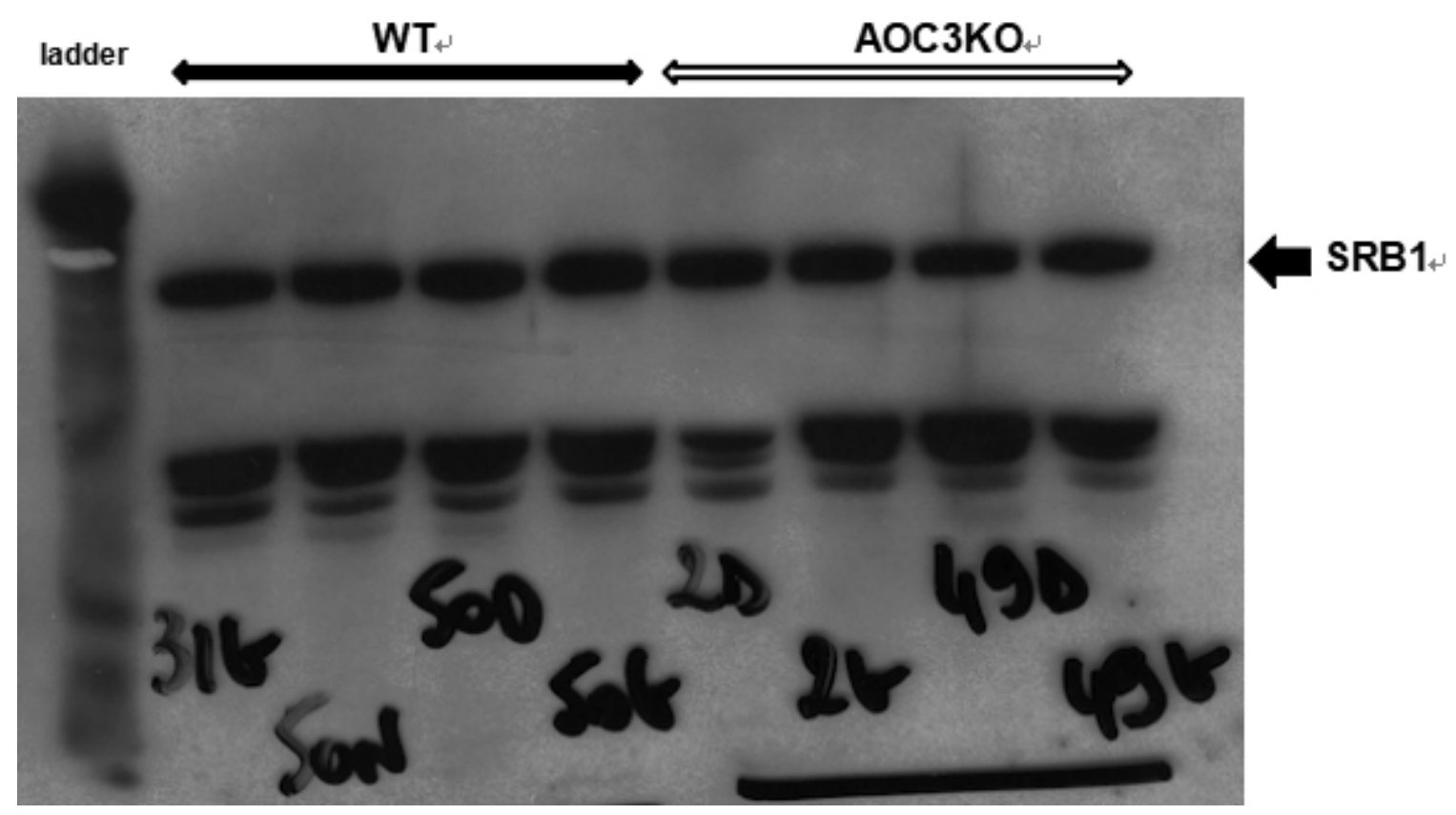

Figure 9. Western blotting of hepatic scavenger receptor class B type 1 in WT and AOC3KO mice. An integral representative WB is shown with four lanes loaded with liver extracts from WT (left) and four with AOC3KO mice (right), while the quantification of immunoreactive SR-B1 proteins was determined on a total of eight mice per genotype.

\section{Oxidative stress and aorta NO bioavailability in AOC3KO mice}

It was investigated whether the lack of Aoc 3 was modifying risk factors of atherosclerosis other than the abnormal cholesterol levels. Indeed, as the VAP-1/SSAO activity generates highly reactive end products (ammonia, aldehydes and hydrogen peroxide), it might interfere with signaling effects in endothelial cells, especially because reactive oxygen species (ROS) and nitric oxide (NO) can have opposite effects in vessels. Thus, alongside elevated cholesterol esterification, fat depot hypertrophy and impaired leukocyte trafficking, the absence of VAP-1/SSAO could have a pronounced effect on vasodilation. However, in this case, the expected lowered generation of highly reactive products could be considered protective a priori. We therefore explored whether the Aoc 3 invalidation was influencing the hydrogen peroxide production in tissues and the levels of nitrite, which can indicate the effectiveness of NO. In this approach, several biological markers or risk factors were also determined in plasma and urine, such as uric acid. Regarding the latter, which is a product of purine nucleotide breakdown, no change was found in plasma or urine, as was also the case for urinary creatinine and urea [Table 4]. Our interpretation is that the invalidation of VAP1/SSAO activity did not diminish ammonia production in a dramatic manner that could alter the production of nitrogen metabolic waste or the kidney function in mice. Similarly, the lack of alteration in plasma levels of fructosamine and AGEs [Table 4] excluded the occurrence of excessive oxidative stress and crosslinking, leading to deleterious glycation and vascular complications such as increased permeability or inhibition of dilation by interfering with NO.

By contrast, the spontaneous hydrogen peroxide release found in aorta and adipose depots was reduced in AOC3KO mice [Table 4]. Since, in the presence of $0.1 \mathrm{mM}$ benzylamine, these tissues also produced less hydrogen peroxide in AOC3KO than in WT mice, it can be attested that VAP-1/SSAO contributes, together with other hydrogen peroxide generating enzymes, to the basal production of ROS and thereby might deplete the bioactivity of NO, by its increased conversion to cytotoxic peroxynitrite. 
Table 4. Plasma levels of oxidative stress and glycation biomarkers, tissue hydrogen peroxide release, nitrite/nitrate content and daily urinary excretion of creatinine, uric acid and urea in WT and AOC3KO mice

\begin{tabular}{|c|c|c|}
\hline & WT & АОСзКо \\
\hline \multicolumn{3}{|l|}{ Plasma levels } \\
\hline AGEs (fluorescence relative units) & $5.78 \pm 0.38(7)$ & $6.23 \pm 0.62(9)$ \\
\hline Fructosamine $(\mu \mathrm{mol} / \mathrm{L})$ & $204.4 \pm 7.4(8)$ & $214.4 \pm 7.8(8)$ \\
\hline Uric acid $(\mu \mathrm{mol} / \mathrm{L})$ & $265.3 \pm 27.4(8)$ & $239.1 \pm 22.8(8)$ \\
\hline \multicolumn{3}{|c|}{ Hydrogen peroxide release ( $\mathrm{nmol} / \mathrm{min} / \mathrm{mg}$ protein) } \\
\hline SCWAT basal & $0.09 \pm 0.004(4)$ & $0.02 \pm 0.01(4)^{\star \star}$ \\
\hline SCWAT benzylamine $0.1 \mathrm{mM}$ & $0.39 \pm 0.02(4)$ & $0.04 \pm 0.02(4)^{\star \star \star \star}$ \\
\hline Aorta basal & $0.10 \pm 0.01(4)$ & $0.04 \pm 0.01(4)^{\star}$ \\
\hline Aorta benzylamine $0.1 \mathrm{mM}$ & $0.20 \pm 0.01(4)$ & $0.06 \pm 0.01(4)^{\star \star \star}$ \\
\hline \multicolumn{3}{|l|}{ Nitrate/Nitrite levels $(\mathrm{nmol} / \mathrm{g})$} \\
\hline Kidney Nitrite & $8.3 \pm 0.9(8)$ & $11.3 \pm 0.8(8)^{\star}$ \\
\hline Kidney Nitrate & $167.3 \pm 45.1(8)$ & $95.4 \pm 15.7(8)$ \\
\hline Kidney $\mathrm{NO}_{3} / \mathrm{NO}_{2}$ ratio & $23.5 \pm 6.6$ & $9.1 \pm 1.6^{\star}$ \\
\hline Heart Nitrite & $20.5 \pm 1.9(8)$ & $30.3 \pm 3.0(8)^{\star}$ \\
\hline Heart Nitrate & $40.3 \pm 5.4(8)$ & $46.8 \pm 4.7(8)$ \\
\hline Heart $\mathrm{NO}_{3} / \mathrm{NO}_{2}$ ratio & $2.1 \pm 0.3$ & $1.9 \pm 0.5$ \\
\hline \multicolumn{3}{|l|}{ Daily urine emission } \\
\hline Creatinine ( $\mu \mathrm{mol} /$ day/mouse) & $5.03 \pm 0.24(10)$ & $4.49 \pm 0.41(10)$ \\
\hline Uric acid ( $\mu \mathrm{mol} /$ day/mouse) & $0.66 \pm 0.06(10)$ & $0.57 \pm 0.09(10)$ \\
\hline Urea (mmol/day/mouse) & $1.14 \pm 0.08(10)$ & $0.90 \pm 0.12(10)$ \\
\hline
\end{tabular}

Mean \pm SEM of the number of cases indicated in parentheses. $\mathrm{H}_{2} \mathrm{O}_{2}$ release was measured without any addition or in the presence of 0.1 mM for 30 min at room temperature. Differences between WT and AOC3KO mice significant at: ${ }^{\star} P<0.05,{ }^{\star \star} P<0.01,{ }^{\star \star \star} P<0.001$.

When considering that the detection of $\mathrm{NO}$ radicals in biological tissues is particularly difficult due to the short lifetime, the levels of nitrite (stable metabolite of NO) can indicate the effectiveness of NO, while the ratio of nitrate to nitrite can be used to assess the oxidative metabolism of $\mathrm{NO}^{[37]}$. The nitrite concentration in heart and kidney was higher in AOC3KO than in WT mice and suggested that there was an enhanced $\mathrm{NO}$ bioavailability in the vasculature when the generation of the reactive products of amine oxidation (mainly $\mathrm{H}_{2} \mathrm{O}_{2}$ and aldehydes) was blunted by Aoc3 gene invalidation [Table 4].

Taken together, these results indicate that, contrary to the enhanced risk factor of atherosclerosis that represented hypercholesterolemia, the $\mathrm{AOC} 3 \mathrm{KO}$ mice did not exhibit signs of enhanced oxidative stress, or decreased nitric oxide (NO) production and/or bioavailability, which might explain why no sign of cardiovascular dysfunction has been reported in this model thus far.

\section{DISCUSSION}

Increased body weight gain was the most evident of the reported phenotypic traits of mice homozygous for the Aoc3 gene null mutation. The overweight phenotype was mainly due to fattening and the larger fat depots of AOCзKO mice could even enlarge further under high-fat feeding. However, when subjected to HFD, the AOCзKO mice were no more obese than WT mice. Despite such defects, the mice lacking Aoc3 were not resistant to insulin (regarding basal insulinemia, insulin secretion after glucose load and antilipolytic responses of adipocytes). However, their mild obesity was accompanied by disturbed circulating lipid profile and increased cholesteryl ester accumulation. Obviously, the AOCзKO mice were totally devoid of VAP-1/SSAO activity in any of the tissues studied, confirming that Aoc 3 gene expression is much higher than that of $A o c 1$ and Aoc2, the other members of the copper-containing amine oxidase family 

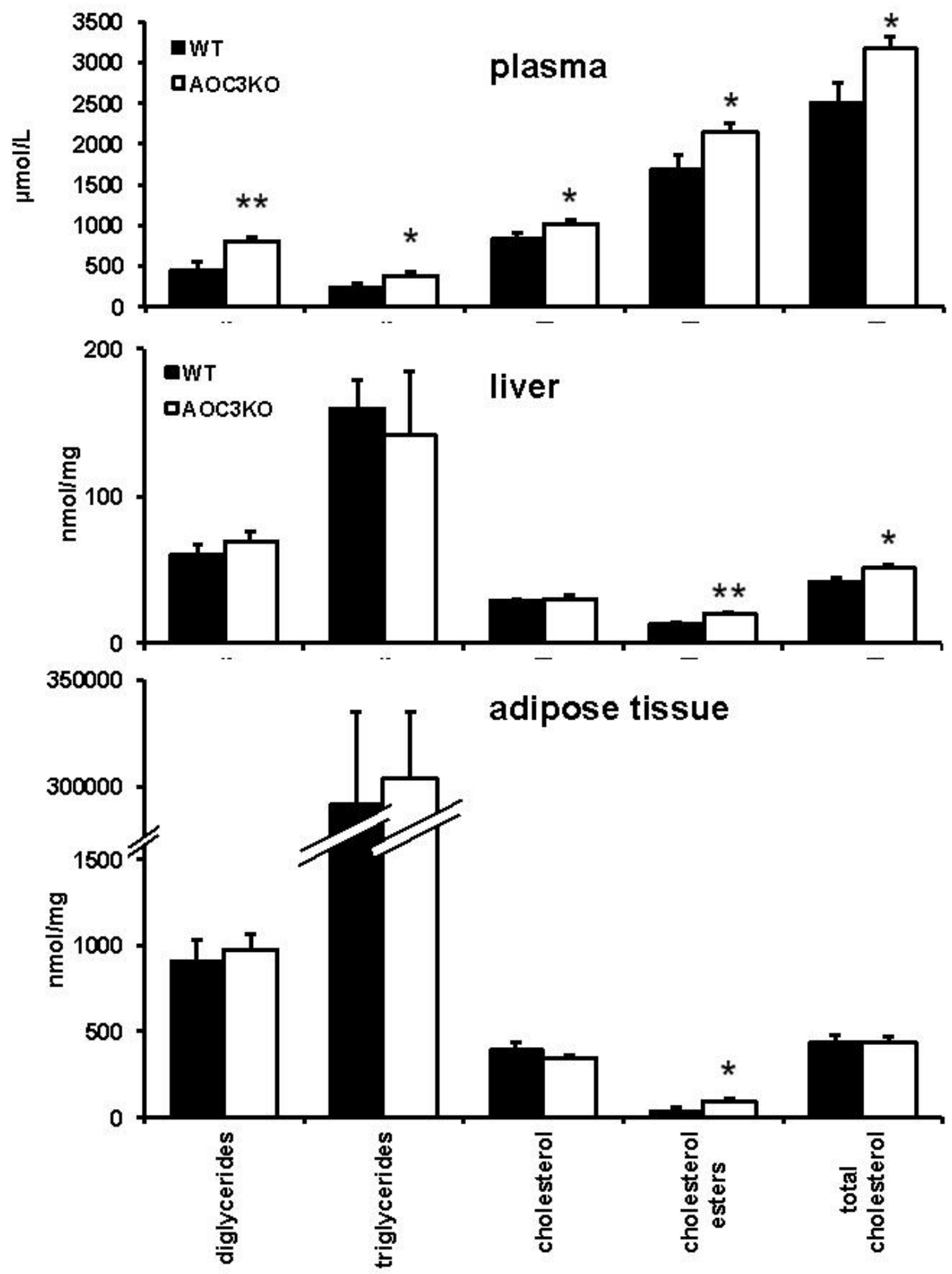

Figure 10. Lipid composition of plasma, liver and adipose tissue in AOC3KO and WT mice. The different lipid classes were determined as specified in Methods in: plasma (top); liver (middle); and white adipose tissue (bottom) (with two scales on the y-axis). Each column represents the mean \pm SEM of eight determinations. Significant difference between genotypes at: ${ }^{\star} P<0.05 ;{ }^{\star \star} P<0.01$. 
(reviewed $\mathrm{in}^{[6]}$ ). In the WT control mice, WAT was confirmed to be the richest anatomical location regarding SSAO activity, irrespective of the technique or data normalization used for enzyme kinetics. Aorta also expressed a high VAP-1/SSAO activity, in agreement with previous findings demonstrating that Aoc 3 knockout mice have increased arterial diameter associated with normal arterial mechanical properties ${ }^{[30]}$. However, in blood vessels, there is another amine oxidase, the vascular lysyl oxidase, which contributes with VAP-1/SSAO to arterial wall remodeling and is predominantly involved in the regulation of arterial stiffness. Nevertheless, VAP-1/SSAO has recently been shown to play a significant role in cardiovascular pathologies since it contributes to valvular interstitial cell calcification and is increased in individuals with calcific aortic valve stenosis ${ }^{[38]}$. Regardless, as a consequence of the substantial expression of VAP-1/SSAO in adipose tissue, the present study and its discussion are focused on the links among cholesterol accumulation, inflammation, oxidative stress and atherosclerosis, by investigating events at the adipocyte and hepatic levels, rather than exploring directly vascular syndromes.

Although the mechanism underlying the fat store enlargement of AOC3KO mice remains unknown, their obese phenotype recalls the obesity evidenced in mice invalidated for other adhesion molecules such as ICAM-1 and Mac- $1^{[39]}$ and in mice lacking of mature lymphocytes ${ }^{[40]}$, suggesting that lymphocytes contribute to the physiological management of lipid storage by adipocytes in fat depots. When subjected to the obesogenic HFD, both the SVF composition and the weight of WAT were similar in WT and AOC3KO mice. With normal feeding, the lower proportion of inflammatory cells among all the cell types present in the stromal fraction was also similar in WT and $\mathrm{AOC} 3 \mathrm{KO}$, but the WAT of the latter was larger. It therefore appeared that, as for the models with defective lymphocyte presence in WAT, the spontaneous obesity of AOC3KO mice occurred without evident sign of WAT inflammation. Although HFD was affecting this aspect, it did not enhance the differences between WT and AOC3KO regarding cholesterol handling and was not considered as an appropriate challenge for our investigations relative to atherosclerosis risk factors.

Since reverse cholesterol transport is an important cardioprotective mechanism, we aimed to test whether a decrease in cholesterol efflux was involved in the spontaneous hypercholesterolemia of AOC3KO mice. While the expression of cholesterol transporters ABCA1 and Scarb1 was deeply reduced in liver ${ }^{[4]}$, the hepatic levels of the SR-B1 carrier were only faintly reduced in AOC3KO mice in the present study. Moreover, the expression of these transporters was not altered in adipocytes devoid of VAP-1/SSAO. Whether a limited cholesterol efflux is primarily involved in the hypercholesterolemia found in the absence of VAP-1/SSAO remains to be determined. There are probably other mechanisms by which VAP-1/SSAO contributes to lipid metabolism and prevents hepatic lipid accumulation. In adipocytes, SSAO/VAP-1 is colocalized with CD36 and SR-B1 in caveolae and is therefore supposed to be involved in the lipid trafficking into and out of these cells ${ }^{[13]}$. The VAP-1/SSAO expression in hepatocytes, which is clearly lower than in adipocytes, does not equally support such substantial contribution to reverse cholesterol transport. In this way, the mice with Aoc3 null mutation have already been described to be devoid of hepatic steatosis ${ }^{[33]}$, a finding consistent with the present observations. As in the present study, when these mice were fed a HFD, they did not develop a higher degree of fatty liver disease than WT control ${ }^{[33]}$. Moreover, we observed that their hypercholesterolemia was positively linked to overweight, as was the case for WT. Similarly, when challenged with gut microbial flagellin, which somewhat reproduces the HFD-induced hepatic steatosis in WT mice, the AOC3KO mice were protected ${ }^{[33]}$. In the elegant study performed by Toivonen and coworkers, a reduced number of $\mathrm{CD} 45$ positive inflammatory cells was found in AOC3KO WAT, as in the present study. Again, the mechanism proposed by the authors implicated the crucial role of adipocyte VAP-1/SSAO, which was essential for the inflammatory response of INWAT to flagellin administration and for the subsequent increase in lipolysis that supplied lipids for hepatic steatosis in $\mathrm{WT}^{[33]}$. Another converging observation between these two studies is that the reduced number of 
inflammatory cells found in AOC3KO WAT when compared to WT could not be readily reversed by challenges such as HFD (in the present study) or microbial flagellin ${ }^{[33]}$. This did not prevent however the occurrence of changes in the relative proportions of macrophages and lymphocytes in this limited population of $\mathrm{CD}_{4} 5^{+}$cells (e.g., increase of $\mathrm{F} 4 / 80$ and $\mathrm{CD} 11 \mathrm{~b}$ positive cells). In other murine models of hepatic injury (methionine choline-deficient diet or diet rich in trans fats and fructose), the absence of functional VAP-1/SSAO reduced inflammatory cell recruitment to the liver and attenuated liver fibrosis ${ }^{[29]}$. Therefore, in these models, steatohepatitis was present in WT mice but was particularly limited in AOC3KO mice or under SSAO inhibition ${ }^{[29]}$. This led to suggesting that targeting the semicarbazide sensitive amine oxidase capacity of VAP-1 may represent a useful therapeutic strategy in nonalcoholic steatohepatitis, especially when considering that the increase in hepatic VAP-1/SSAO expression occurring in liver diseases can amplify steatosis, metabolic disturbance and inflammation ${ }^{[4]}$. Although our results do not reveal the underlying mechanisms, they are in complete agreement with this proposed novel therapeutic approach since they describe a lack of fatty liver despite the pronounced spontaneous hypercholesterolemia of AOC3KO mice.

Alongside defects in cholesterol efflux, the synthesis of cholesterol seemed to be enhanced in WAT since adipocyte $H M G C o A$ reductase expression was increased in AОС $3 \mathrm{KO}$ mice. This finding is not so astonishing since it has been reported that cultured preadipocytes bearing a knockdown for SSAO possess higher abundance of proteins involved in sphingomyelin metabolism and cholesterol biosynthesis, alongside with downregulated glycolysis pathway ${ }^{[14]}$. Experiments with copper deficiency also indicate that SSAO activity, which is dependent on copper for proper function, is involved in the fuel choice for energy supply during adipocyte differentiation ${ }^{[14]}$. Regardless, a limit of our study is that it cannot be stated whether an increase of cholesterol production and/or a decreased LDL capture by WAT was responsible for the increased cholesterol plasma levels, leading to increased esterification rate in liver, in order to keep stable the hepatic free cholesterol.

Whether the turnover of biliary acids (unfortunately not determined here) is altered in AOC3KO mice remains not defined. This issue could probably shed more light on the unexpected body weight gain and cholesterol disturbances we observed without being capable of bringing evidence of increased food intake. Concomitant changes in gut microbiota and bile acid production in our breeding conditions could underlie the increased food efficiency. Indeed, a mild obesity that slowly develops under Aoc3 invalidation has been reported in several ${ }^{[3,4,15]}$ but not all the studies performed on this model ${ }^{[5]}$. In this way, when investigating whether changes in gut microbiota could be associated with flagellin-induced liver fatty disease, Toivonen and coworkers evidenced that the absence of VAP-1/SSAO modulated the composition of gut microbiota $^{[33]}$. Hence, the amine oxidase activity of VAP-1/SSAO, also present in the gut, releases hydrogen peroxide in its vicinity and can exert a local antibacterial action, modifying thereby the diversity of gut microbiota. Whether this may also occur in WAT and liver and probably modifies the less known tissue microbiota $^{[42]}$ deserves further investigations.

Beside hypercholesterolemia, chronic hyperglycemia initiates processes responsible for functional impairment of the blood vessels. Since ROS belong to the vasoconstrictor agents that decrease the availability of the vasodilator NO, it was likely to find a limited hydrogen peroxide generation and signs of increased NO availability in aorta and kidney of AOC3KO mice because hydrogen peroxide is one of the very reactive products of VAP-1/SSAO activity. However, although deleterious at high doses, hydrogen peroxide can act as a signaling agent and it has been found necessary for the antihyperglycemic effect of $\mathrm{B} 6 \mathrm{~V} 10$, a benzylamine-vanadium complex substrate of SSAO ${ }^{[25,26]}$. The loss of antihyperglycemic effect of this compound in $\mathrm{AOC} 3 \mathrm{KO}$ mice and the decreased $\mathrm{H}_{2} \mathrm{O}_{2}$ release in tissues from AOC3KO mice indicated 
that these mice could not perform the oxidation of exogenous amines, and of endogenous substrates as well. This suggests that, under basal conditions, VAP-1/SSAO is continuously oxidizing endogenous substrates, proposed decades ago to be methylamine or aminoacetone ${ }^{[43]}$, but for which the exact nature and turnover remains to be determined.

According to Li and coworkers, the plasma total nitrite levels are lowered in diabetic rats in a manner that is reversed by treatment with SSAO inhibitors ${ }^{[44]}$. Although this reversal is not accompanied with blood glucose normalization, it is concomitant with an improvement of the morphological changes of aorta and kidney in diabetic rats. Thus, for the present study, it was tempting to extrapolate that the genetic invalidation of $A \circ c 3$ was acting in the same way. In $\mathrm{AOC} 3 \mathrm{KO}$, the increased nitrite in heart and kidney, together with the limiting $\mathrm{H}_{2} \mathrm{O}_{2}$ production found in aorta and WAT, could indicate improved NO availability resulting in a similar protective effect on vasculature, albeit a probable impairment of the modest contribution of VAP-1/SSAO to collagen and elastin crosslinking in arterial wall could not be ruled out ${ }^{[45]}$.

Ammonia, another product of amine oxidation, was expected to be produced in lower quantities in AOC3 $\mathrm{KO}$ mice, but it was not determined in our studies since nitrogen metabolism depends on many other pathways than oxidative deamination. Regardless, daily urinary emission of creatinine was not altered after Aoc3 invalidation. Thus, increased uremic toxins due to kidney impairment is not a phenotypic trait of AOCзKO mice, and the daily emissions of creatinine and urea we found in mice used for the present study were not different from those reported in the literature ${ }^{[46,47]}$. This may deal with the recently reported protective effect of SSAO inhibition towards the potential adverse effects of creatine supplementation in diabetic subjects ${ }^{[48]}$.

Numerous controversies are still unsolved after the present complementary descriptive studies on AOC3KO model. First, the mild obesity of these mice strikingly contrasts with the decreased fattening found in rodents treated by pharmacological inhibitors of SSAO, such as hydralazine ${ }^{[49]}$, a fluoroallylamine derivative $e^{[50]}$, semicarbazide ${ }^{[51]}$ or phenelzine ${ }^{[2,53]}$. A better understanding of the selectivity of these inhibitors will help to explain these apparent inconsistencies, as all of them have "off-target" actions (for reviews, see $^{[9,54]}$. Second, the pharmacological inhibition of VAP-1/SSAO has been reported to be beneficial for experimental atherosclerosis in mice and rabbits ${ }^{[5,56]}$. These findings are in agreement with the previously reported reduction of macrophage recruitment in atherosclerotic plaques by VAP-1/SSAO inhibition ${ }^{[11]}$ only when considering the reduced inflammation and not the increased cholesterol of AOC3KO mice. Hence, VAP-1/SSAO inhibition has also been reported by other researchers to aggravate the development of atherosclerotic lesions despite reducing macrophage infiltration ${ }^{[57]}$. Prior to these discordant observations, the group of P. Yu had considered that, since methylamine, one of the SSAO substrates, is oxidized into the deleterious formaldehyde, pharmacological SSAO inhibition blocks the cascade of atherogenic events triggered by this product in diabetic model $s^{[s 8]}$. This paradigm seems to be reinforced by the fact that increased plasma SSAO is a widely recognized alteration of diabetic states ${ }^{[8,59]}$.

Taken together, our findings not only confirm that SSAO activity is highest in WAT, although for still undefined functions, but also corroborate the multiple biological roles played by the product of Aoc3 gene. First, VAP-1/SSAO invalidation tends to increase WAT hypertrophy by still unknown mechanisms (putatively lymphocyte-dependent) and is accompanied by a hypercholesterolemia that may facilitate the formation of atherosclerotic plaques. In contrast, the same VAP-1/SSAO invalidation depresses immune cell recruitment and does not induce any sign of glucose intolerance, insulin resistance or excessive oxidative stress. In addition, it notably does not alter uric acid metabolism and appears to improve NO availability and HDL cholesterol, which are issues that can alleviate atherosclerosis. Thus, there is a complex 
duality in the actions of VAP-1/SSAO regarding atherosclerosis evolution, as was previously noted for its substrates that exert insulin mimicking actions while promoting diabetes-like complications ${ }^{[60]}$.

Overall, the AOC3KO mouse model is not on its own a relevant model for the mechanistic study of atherosclerosis onset and treatment, but it deserves to be studied with other transgenic models (e.g., crossing with ApoE knockout mice), under nutritional and pharmacological approaches to provide a comprehensive view of the role of the "metabolism-inflammation-oxidative stress triad" on the increased risk of coronary artery disease.

\section{DECLARATIONS}

\section{Acknowledgments}

The coauthors thank the staff of animal unit CREFRE, currently headed by Xavier Collet, and especially its Rangueil satellite for housing wild type and transgenic rodents. They also thank the staff of I2MC lipidomic platform, currently headed by Justine Bertrand-Michel, and Jean Jérôme Soueix Skywalker for webmastering. Special acknowledgments to S. Jalkanen, M. Salmi, C. Stolen (Turku University, Finland) for providing AOC3KO founders and antibodies, to E. Wanecq, D. Prévot, M. Nibbelink, H. Lulka and F. Bietrix (Toulouse University, France) for their expertise, and to A. Bouloumié and P. Valet for helpful discussions.

\section{Authors' contributions}

Involved in animal breeding, conducted experiments, and analyzed data: Iffiú-Soltész Z

Performed the mouse and molecular experiments, and data analyses: Bour $\mathrm{S}$

Provided reagents and designed/supported lipidomic approaches: Collet X, Tercé $\mathrm{F}$

Designed experiments, supported ROS and NO experiments, and revised the paper: Szökö E

Designed the studies, performed adipocyte experiments, reviewed the literature, and wrote the manuscript: Carpéné C

\section{Availability of data and materials}

Mice generated and provided by the group of Pr. S. Jalkanen and M. Salmi are available under MTA with their founders.

\section{Financial support and sponsorship}

This work was supported by recurrent INSERM grants for the UMR1048 and partially by the FrenchHungarian collaborative programme Balaton.

\section{Conflicts of interest}

The authors declare that there are no competing financial interests with this work.

\section{Ethical approval and consent to participate}

Mice were housed and manipulated according to the INSERM guidelines in animal care facilities with agreements number A 3155504 and C 3155507. The experimental protocol was approved by the local ethical committee CEEA nb122, and the study was performed according to the ARRIVE guidelines (Animal Research: Reporting of In Vivo Experiments).

\section{Consent for publication}

Not applicable. 


\section{Copyright}

(c) The author(s) 2021.

\section{REFERENCES}

1. Studies Collaboration. Body-mass index and cause-specific mortality in 900000 adults: collaborative analyses of 57 prospective studies. Lancet 2009;373:1083-96. DOI PubMed PMC

2. Reiss AB, Glass DS, Voloshyna I, Glass AD, Kasselman LJ, De Leon J. Obesity and atherosclerosis: the exosome link. VP 2020;4:19. DOI

3. Bour S, Caspar-Bauguil S, Iffiú-Soltész Z, et al. Semicarbazide-sensitive amine oxidase/vascular adhesion protein-1 deficiency reduces leukocyte infiltration into adipose tissue and favors fat deposition. Am J Pathol 2009;174:1075-83. DOI PubMed PMC

4. Jargaud V, Bour S, Tercé F, et al. Obesity of mice lacking VAP-1/SSAO by Aoc3 gene deletion is reproduced in mice expressing a mutated vascular adhesion protein-1 (VAP-1) devoid of amine oxidase activity. J Physiol Biochem 2020. DOI PubMed

5. Stolen CM, Marttila-Ichihara F, Koskinen K, et al. Absence of the endothelial oxidase AOC3 leads to abnormal leukocyte traffic in vivo. Immunity 2005;22:105-15. DOI PubMed

6. de Carvalho L, Bligt-Lindén E, Ramaiah A, Johnson MS, Salminen TA. Evolution and functional classification of mammalian copper amine oxidases. Mol Phylogenet Evol 2019;139:106571. DOI PubMed

7. Salmi M, Jalkanen S. Vascular Adhesion Protein-1: A Cell Surface Amine Oxidase in Translation. Antioxid Redox Signal 2019;30:314-32. DOI PubMed PMC

8. Boomsma F, Bhaggoe UM, van der Houwen AM, van den Meiracker AH. Plasma semicarbazide-sensitive amine oxidase in human (patho)physiology. Biochimica et Biophysica Acta (BBA) - Proteins and Proteomics 2003;1647:48-54. DOI PubMed

9. Carpéné C, Boulet N, Chaplin A, Mercader J. Past, Present and Future Anti-Obesity Effects of Flavin-Containing and/or CopperContaining Amine Oxidase Inhibitors. Medicines (Basel) 2019;6:9. DOI PubMed PMC

10. Dunkel P, Balogh B, Meleddu R, Maccioni E, Gyires K, et al. Semicarbazide-sensitive amine oxidase/vascular adhesion protein-1: a patent survey. Expert Opin Ther Pat 2011;21:1453-71. DOI PubMed

11. Silvola JM, Virtanen H, Siitonen R, Hellberg S, Liljenback H, et al. Leukocyte trafficking-associated vascular adhesion protein 1 is expressed and functionally active in atherosclerotic plaques. Sci Rep 2016;6:35089. DOI PubMed PMC

12. Reiss AB, Wan DW, Anwar K, Merrill JT, Wirkowski PA, et al. Enhanced CD36 scavenger receptor expression in THP-1 human monocytes in the presence of lupus plasma: linking autoimmunity and atherosclerosis. Exp Biol Med (Maywood) 2009;234:354-60. DOI PubMed PMC

13. Souto RP, Vallega G, Wharton J, Vinten J, Tranum-Jensen J, et al. Immunopurification and characterization of rat adipocyte caveolae suggest their dissociation from insulin signaling. J Biol Chem 2003;278:18321-9. DOI PubMed

14. Yang H, Ralle M, Wolfgang MJ, Dhawan N, Burkhead JL, et al. Copper-dependent amino oxidase 3 governs selection of metabolic fuels in adipocytes. PLoS Biol 2018;16:e2006519. DOI PubMed PMC

15. Noonan T, Lukas S, Peet GW, Pelletier J, Panzenbeck M, et al. The oxidase activity of vascular adhesion protein-1 (VAP-1) is essential for function. Am J Clin Exp Immunol 2013;2:172-85. PubMed PMC

16. Iffiu-Soltesz Z, Wanecq E, Lomba A, Portillo MP, Pellati F, et al. Chronic benzylamine administration in the drinking water improves glucose tolerance, reduces body weight gain and circulating cholesterol in high-fat diet-fed mice. Pharmacol Res 2010;61:355-63. DOI PubMed

17. Morin N, Visentin V, Calise D, Marti L, Zorzano A, et al. Tyramine stimulates glucose uptake in insulin-sensitive tissues in vitro and in vivo via its oxidation by amine oxidases. $J$ Pharmacol Exp Ther 2002;303:1238-47. DOI PubMed

18. Leroux M, Lemery T, Boulet N, Briot A, Zakaroff A, et al. Effects of the amino acid derivatives, $\beta$-hydroxy- $\beta$-methylbutyrate, taurine, and N-methyltyramine, on triacylglycerol breakdown in fat cells. J Physiol Biochem 2019;75:263-73. DOI PubMed

19. Bligh EG, Dyer WJ. A rapid method of total lipid extraction and purification. Can J Biochem Physiol 1959;37:911-7. DOI PubMed

20. Vieu C, Jaspard B, Barbaras R, Manent J, Chap H, et al. Identification and quantification of diacylglycerols in HDL and accessibility to lipase. J Lipid Res 1996;37:1153-61. PubMed

21. Wu JT, Tu MC, Zhung P. Advanced glycation end product (AGE): characterization of the products from the reaction between Dglucose and serum albumin. J Clin Lab Anal 1996;10:21-34. DOI PubMed

22. Szökő E, Tábi T, Halász A, Pálfi M, Magyar K. High sensitivity analysis of nitrite and nitrate in biological samples by capillary zone electrophoresis with transient isotachophoretic sample stacking. J Chromatogr ;1051:177-83. DOI PubMed

23. Les F, Deleruyelle S, Cassagnes LE, Boutin JA, Balogh B, et al. Piceatannol and resveratrol share inhibitory effects on hydrogen peroxide release, monoamine oxidase and lipogenic activities in adipose tissue, but differ in their antilipolytic properties. Chem Biol Interact 2016;258:115-25. DOI PubMed

24. Carpéné C, Desquesnes A, Gomez-Ruiz A, Iffiu-Soltesz Z, Le Gonidec S, et al. Long-term activation of semicarbazide-sensitive amine oxidase lowers circulating levels of uric acid in diabetic conditions. Physiol Res 2012;61:251-7. DOI PubMed

25. Garcia-Vicente S, Yraola F, Marti L, Gonzalez-Munoz E, Garcia-Barrado MJ, et al. Oral insulin-mimetic compounds that act independently of insulin. Diabetes 2007;56:486-93. DOI PubMed

26. Yraola F, Garcia-Vicente S, Marti L, Albericio F, Zorzano A, et al. Understanding the mechanism of action of the novel SSAO substrate (C7NH10)6(V10O28).2H2O, a prodrug of peroxovanadate insulin mimetics. Chem Biol Drug Des 2007;69:423-8. DOI PubMed

27. Stolen CM, Yegutkin GG, Kurkijarvi R, Bono P, Alitalo K, et al. Origins of serum semicarbazide-sensitive amine oxidase. Circ Res 


\section{4;95:50-7. DOI PubMed}

28. Marttila-Ichihara F, Smith DJ, Stolen C, Yegutkin GG, Elima K, et al. Vascular amine oxidases are needed for leukocyte extravasation into inflamed joints in vivo. Arthritis Rheum 2006;54:2852-62. DOI PubMed

29. Weston CJ, Shepherd EL, Claridge LC, Rantakari P, Curbishley SM, et al. Vascular adhesion protein-1 promotes liver inflammation and drives hepatic fibrosis. J Clin Invest 2015;125:501-20. DOI PubMed PMC

30. Mercier N, Osborne-Pellegrin M, El Hadri K, Kakou A, Labat C, et al. Carotid arterial stiffness, elastic fibre network and vasoreactivity in semicarbazide-sensitive amine-oxidase null mouse. Cardiovasc Res 2006;72:349-57. DOI PubMed

31. Bour S, Prévot D, Guigne C, Stolen C, Jalkanen S, et al. Semicarbazide-sensitive amine oxidase substrates fail to induce insulin-like effects in fat cells from AOC3 knockout mice. J Neural Transm (Vienna) 2007;114:829-33. DOI PubMed

32. Gres S, Bour S, Valet P, Carpene C. Benzylamine antihyperglycemic effect is abolished by AOC3 gene invalidation in mice but not rescued by semicarbazide-sensitive amine oxidase expression under the control of aP2 promoter. J Physiol Biochem 2012;68:651-62. DOI PubMed

33. Toivonen R, Vanhatalo S, Hollmén M, Munukka E, Keskitalo A, et al. Vascular Adhesion Protein 1 mediates gut microbial flagellininduced inflammation, leukocyte infiltration, and hepatic steatosis. Sci 2019;1:65.

34. Champy MF, Selloum M, Piard L, Zeitler V, Caradec C, et al. Mouse functional genomics requires standardization of mouse handling and housing conditions. Mamm Genome 2004;15:768-83. DOI PubMed

35. Boulet N, Estève D, Bouloumié A, Galitzky J. Cellular heterogeneity in superficial and deep subcutaneous adipose tissues in overweight patients. J Physiol Biochem 2013;69:575-83. DOI PubMed

36. Sablé R, Sicart R, Berry E. Steroid pattern of bile and feces in response to a fruit-enriched diet in hypercholesterolemic hamsters. Ann Nutr Metab 1990;34:303-10. DOI PubMed

37. Kobayashi T, Kamata K. Effect of chronic insulin treatment on NO production and endothelium-dependent relaxation in aortae from established STZ-induced diabetic rats. Atherosclerosis 2001;155:313-20. DOI PubMed

38. Mercier N, Pawelzik SC, Pirault J, Carracedo M, Persson O, et al. Semicarbazide-Sensitive Amine Oxidase Increases in Calcific Aortic Valve Stenosis and Contributes to Valvular Interstitial Cell Calcification. Oxid Med Cell Longev 2020;2020:5197376. DOI PubMed PMC

39. Dong ZM, Gutierrez-Ramos JC, Coxon A, Mayadas TN, Wagner DD. A new class of obesity genes encodes leukocyte adhesion receptors. Proc Natl Acad Sci U S A 1997;94:7526-30. DOI PubMed PMC

40. Liu X, Huh JY, Gong H, Chamberland JP, Brinkoetter MT, et al. Lack of mature lymphocytes results in obese but metabolically healthy mice when fed a high-fat diet. Int J Obes (Lond). 2015;39:1548-57. DOI PubMed PMC

41. Shepherd EL, Karim S, Newsome PN, Lalor PF. Inhibition of vascular adhesion protein-1 modifies hepatic steatosis in vitro and in vivo. World J Hepatol 2020;12:931-48. DOI PubMed PMC

42. Tilg H, Burcelin R, Tremaroli V. Liver tissue microbiome in NAFLD: next step in understanding the gut-liver axis? Gut 2020;69:1373-4. DOI PubMed

43. Lyles GA. Substrate-specificity of mammalian tissue-bound semicarbazide-sensitive amine oxidase. Prog Brain Res 1995;106:293303. DOI PubMed

44. Li C, Wang Z, Li X, Chen J. Effects of semicarbazide-sensitive amine oxidase inhibitors on morphology of aorta and kidney in diabetic rats. BMC Endocr Disord 2019;19:59. DOI PubMed PMC

45. Mercier N, El Hadri K, Osborne-Pellegrin M, Nehme J, Perret C, et al. Modifications of arterial phenotype in response to amine oxidase inhibition by semicarbazide. Hypertension 2007;50:234-41. DOI PubMed

46. Takahashi N, Boysen G, Li F, Li Y, Swenberg JA. Tandem mass spectrometry measurements of creatinine in mouse plasma and urine for determining glomerular filtration rate. Kidney Int 2007;71:266-71. DOI PubMed

47. Cherezova A, Tomilin V, Buncha V, Zaika O, Ortiz PA, et al. Urinary concentrating defect in mice lacking Epac1 or Epac2. Faseb $j$ 2019;33:2156-70. DOI PubMed PMC

48. Papukashvili D, Rcheulishvili N, Deng Y. Beneficial impact of Semicarbazide-Sensitive Amine Oxidase inhibition on the potential cytotoxicity of creatine supplementation in type 2 diabetes mellitus. Molecules 2020;25:2029. DOI PubMed PMC

49. Carroll JF, King JW, Cohen JS. Hydralazine treatment alters body composition in the rabbit model of obesity. Acta Physiol Scand 2004;181:183-91. DOI PubMed

50. Yu PH, Wang M, Fan H, Deng Y, Gubisne-Haberle D. Involvement of SSAO-mediated deamination in adipose glucose transport and weight gain in obese diabetic KKAy mice. Am J Physiol Endocrinol Metab 2004; 286:E634-41. DOI PubMed

51. Mercader J, Iffiu-Soltesz Z, Bour S, Carpéné C. Oral administration of semicarbazide limits weight gain together with inhibition of fat deposition and of primary amine oxidase activity in adipose tissue. J Obes 2011;2011:475786. DOI PubMed PMC

52. Carpéné C, Mercader J, Le Gonidec S, Schaak S, Mialet-Perez J, et al. Body fat reduction without cardiovascular changes in mice after oral treatment by the MAO inhibitor phenelzine. Br J Pharmacol 2018;175:2428-40. DOI PubMed PMC

53. Mercader J, Sabater A, Le Gonidec S, Decaunes P, Chaplin A, et al. Oral phenelzine treatment mitigates metabolic disturbances in mice fed a high-fat diet. J Pharmacol Exp Ther 2019; 371:555-66. DOI PubMed

54. Papukashvili D, Rcheulishvili N, Deng Y. Attenuation of Weight Gain and Prevention of Associated Pathologies by Inhibiting SSAO. Nutrients 2020;12:184. DOI PubMed PMC

55. Wang SH, Yu TY, Tsai FC, Weston CJ, Lin MS, et al. Inhibition of semicarbazide-sensitive amine oxidase reduces atherosclerosis in apolipoprotein E-deficient mice. Transl Res 2018; 197:12-31. DOI PubMed

56. Wang SH, Yu TY, Hung CS, Yang CY, Lin MS, et al. Inhibition of semicarbazide-sensitive amine oxidase reduces atherosclerosis in cholesterol-fed New Zealand white rabbits. Sci Rep 2018;8:9249. DOI PubMed PMC 
57. Zhang M, Liu L, Zhi F, Niu P, Yang M, et al. Inactivation of semicarbazide-sensitive amine oxidase induces the phenotypic switch of smooth muscle cells and aggravates the development of atherosclerotic lesions. Atherosclerosis 2016;249:76-82. DOI PubMed

58. Yu PH, Wang M, Deng YL, Fan H, Shira-Bock L. Involvement of semicarbazide-sensitive amine oxidase-mediated deamination in atherogenesis in KKAy diabetic mice fed with high cholesterol diet. Diabetologia 2002;45:1255-62. DOI PubMed

59. Aalto K, Maksimow M, Juonala M, Viikari J, Jula A, et al. Soluble vascular adhesion protein-1 correlates with cardiovascular risk factors and early atherosclerotic manifestations. Arterioscler Thromb Vasc Biol 2012;32:523-32. DOI PubMed

60. Stolen CM, Madanat R, Marti L, Kari S, Yegutkin GG, et al. Semicarbazide sensitive amine oxidase overexpression has dual consequences: insulin mimicry and diabetes-like complications. Faseb j 2004;18:702-4. DOI PubMed 